\title{
Review Article \\ Presenting a New Standard Drug Model for Turmeric and Its Prized Extract, Curcumin
}

\author{
Franco Cavaleri (iD \\ Biologic Pharmamedical Research, 688-2397 King George Blvd., White Rock, BC, Canada V4A7E9 \\ Correspondence should be addressed to Franco Cavaleri; franco.c@biologic-med.com
}

Received 27 September 2017; Accepted 6 December 2017; Published 15 January 2018

Academic Editor: Ke-Wu Zeng

Copyright (C) 2018 Franco Cavaleri. This is an open access article distributed under the Creative Commons Attribution License, which permits unrestricted use, distribution, and reproduction in any medium, provided the original work is properly cited.

\begin{abstract}
Various parts of the turmeric plant have been used as medicinal treatment for various conditions from ulcers and arthritis to cardiovascular disease and neuroinflammation. The rhizome's curcumin extract is the most studied active constituent, which exhibits an expansive polypharmacology with influence on many key inflammatory markers. Despite the expansive reports of curcucmin's therapeutic value, clinical reliability and research repeatability with curcumin treatment are still poor. The pharmacology must be better understood and reliably mapped if curcumin is to be accepted and used in modern medical applications. Although the polypharmacology of this extract has been considered, in mainstream medicine, to be a drawback, a perspective change reveals a comprehensive and even synergistic shaping of the NF-kB pathway, including transactivation. Much of the inconsistent research data and unreliable clinical outcomes may be due to a lack of standardization which also pervades research standard samples. The possibility of other well-known curcumin by-products contributing in the polypharmacology is also discussed. A new flowchart of crosstalk in transduction pathways that lead to shaping of nuclear NF-kB transactivation is generated and a new calibration or standardization protocol for the extract is proposed which could lead to more consistent data extraction and improved reliability in therapy.
\end{abstract}

\section{Introduction}

Turmeric is a spice used for thousands of years in IndoAsian culinary recipes, a significant component of most curry powders $[1,2]$. The bright orange-yellow powder that is derived from the boiled, dried, and crushed turmeric rhizome is also used as a potent natural dye and food colouring agent even today [3, 4]. Various parts of the turmeric plant have been used as medicinal treatment for various conditions from ulcers [5] and arthritis [6] to cardiovascular disease [7] and neuroinflammation [8]. Turmeric plays a central role in Ayurveda and other traditional medicines [5, 9-11]. The rhizome's naturally occurring curcuminoid analogues are likely the most studied active constituents [12]; however, the perennial plant contains many other active constituents including a water-soluble peptide, turmerin, and essential oils including turmerones and zingiberene that can contribute pharmacology of their own [13-16].

The curcumin extract, although relatively isolated from the rest of the plant's constituents, still exhibits an expansive polypharmacology $[17,18]$. The extract is made up of three main curcuminoid analogues: diferuloylmethane (curcumin I), desmethoxycurcumin (curcumin II), and bisdesmethoxycurcumin (curcumin III) [19]. Each curcuminoid analogue is similar in structure as shown in Figure 1. As we see displayed in Figures 2 and 3, the curcumin extract with its three naturally occurring curcumin analogues targets multiple subcellular proteins in a broad manner [20-22]. This polypharmacology may be a function of the nonspecific activity by each curcuminoid analogue on different targets, but it may also be a function of other factors that will be discussed.

Curcumin has been shown to influence many key biological markers of inflammation such as NF-kB $[23,24]$ and C-reactive protein [25]; growth factors and growth factor receptors [26]; eicosanoid enzymes such as cyclooxygenase (COX) inhibition [27]; tumor suppressor proteins such as p53 [28]; lipoxygenase (LOX) inhibition [29]; and inhibition of BACE1 and $\beta$-amyloid aggregation to potentially deliver benefits in Alzheimer's treatment [30-32]. Curcumin modulates 


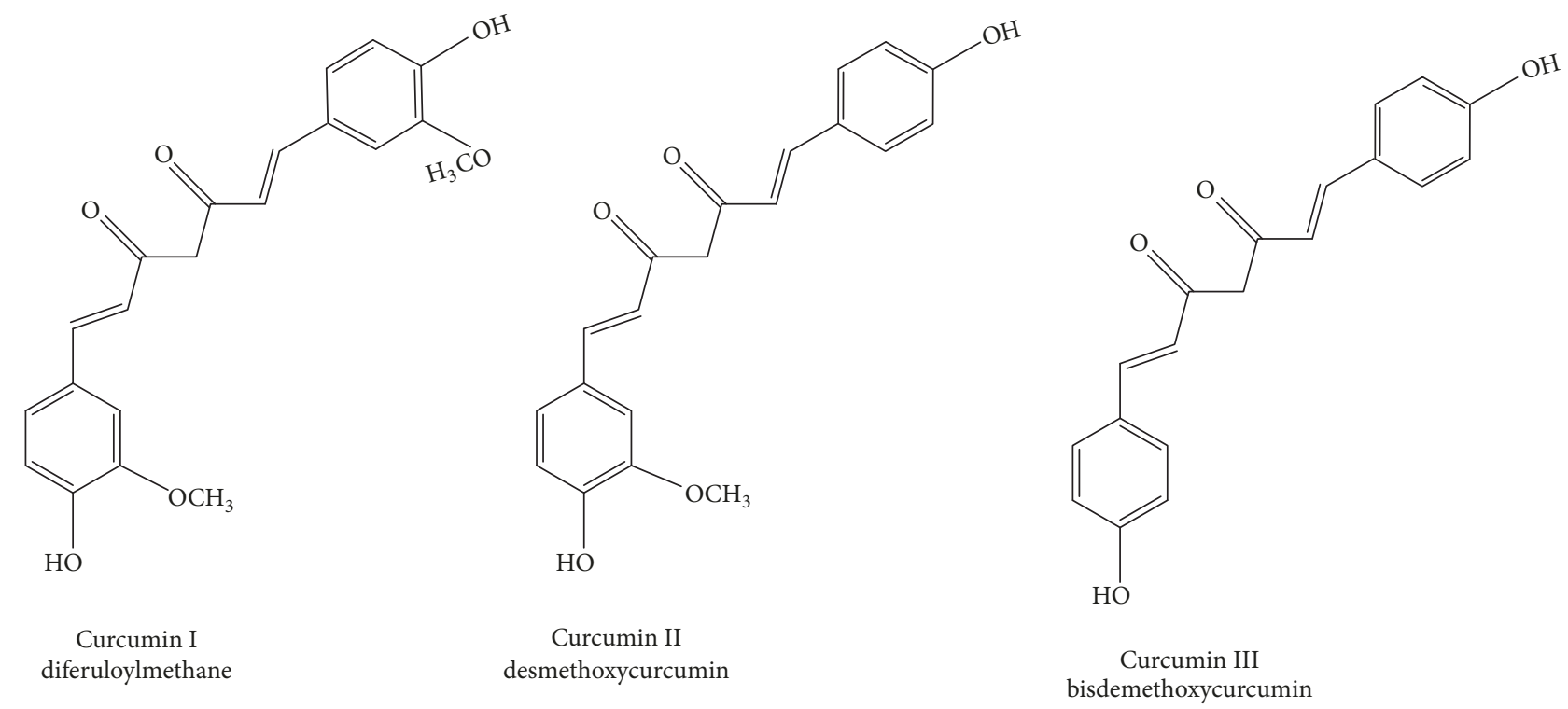

FIgURE 1: Comparing the structure of the three curcuminoids.

various cytokines such as inhibition of interleukins $1,2,6$, 8 , and $12, \operatorname{TNF} \alpha$, and $\operatorname{IFN} \gamma[24,33,34]$, while inducing the anti-inflammatory IL-10 $[35,36]$. Curcumin is also shown to inhibit expression of CD80, CD86, and MHC II in T-cells [33].

However, reliability and research repeatability with this therapeutic agent are still falling short [37]. This may be due to the fact that the initiative has not been taken to establish a standardization protocol for the natural medicinal agent that will set in motion consistent specifications for the curcumin research standard samples being studied. Other factors contributing to the pharmacology such as the wellknown curcumin degradation by-products $[38,39]$ are also likely playing a role.

In this review, curcumin's pharmacology will be discussed in the context of NF-kB-related proteins and their signalling pathways and other subcellular pathways that the extract successfully targets. A new calibration or standardization protocol is proposed with hopes that it may help set the stage for more consistent data extraction and improved reliability in therapy. This correction may facilitate health care professionals' trust in the treatment of inflammatory disorders with curcumin-based therapies.

\section{Inflammation and the NF-kB Signalling Pathway}

Inflammation is a broad term used to describe a complex process by which the body recruits immune system and other biochemicals to eliminate pathogens, autoreactive self-cells and dead cells, and start in motion a restorative and recovery process. Inflammation is characterised by swelling, heat, and pain [40] as we see with acute conditions such as injury. However, the subcellular events associated with inflammation are quite complex and are more recently associated with chronic systemic illnesses that at first thought appear to be far removed from the inflammatory process [41] including the pathophysiology of hypertension [42], atherosclerosis [43], depression [44, 45], and diabetes [46]. Obesity, in fact, is closely linked with inflammation as white adipose cells secrete inflammatory cytokines and adipokines that exacerbate systemic proinflammatory state, insulin resistance, and general morbidity [47-49]. The NF-kB family of proteins, RelA (p65), RelB, and c-Rel, and p100 and p105 which subsequently degrade to form p52 and p50, respectively, [50] are central to the regulation of inflammation [51]. To be able to present the full scope of NF-kB regulation and the transcription factor expression of its cognate genes could take a small book. However, here a selected understanding of the transcription factor's interactivity in the framework of the curcumin extract's pharmacology will be discussed.

Beyond even inflammation, NF-kB is a transcription factor that regulates networks which maintain cell health and survival and also plays a common and central role in disease pathology $[52,53]$. The transcription factor system is a central mediator and conductor of the immune, inflammatory, oxidative, and stress responses [54-56]. It plays a central role in the mechanism of cancer, viral, and bacterial induction and survival $[57,58]$. In fact, host responsiveness to viral infection such as with TNF $\alpha$ synthesis can, itself, activate NF$\mathrm{kB}$ binding to DNA and transactivation to convert viruses like HIV-1 into their active forms [59].

The NF-kB family of proteins partakes in a complex expression of as many as 150 genes [55, 60-63] including key cytokines central to regulation of inflammatory and immune system activity: interleukin 2 (IL-2) $[64,65]$, interleukin 6 (IL-6) [66], interleukin 8 (IL-8) [67], interleukin 12 (IL-12) [68], TNF- $\alpha$ [69], and interleukin 1 (IL-1) [70]. Mutations of genes, such as NFkBIA, transcribing p65-p50 inhibitor protein, and I-kappa-B, are shown to be involved in the pathophysiology of autoimmune disorders where the transcription factor is uncontrollably freed to deliver constitutive 


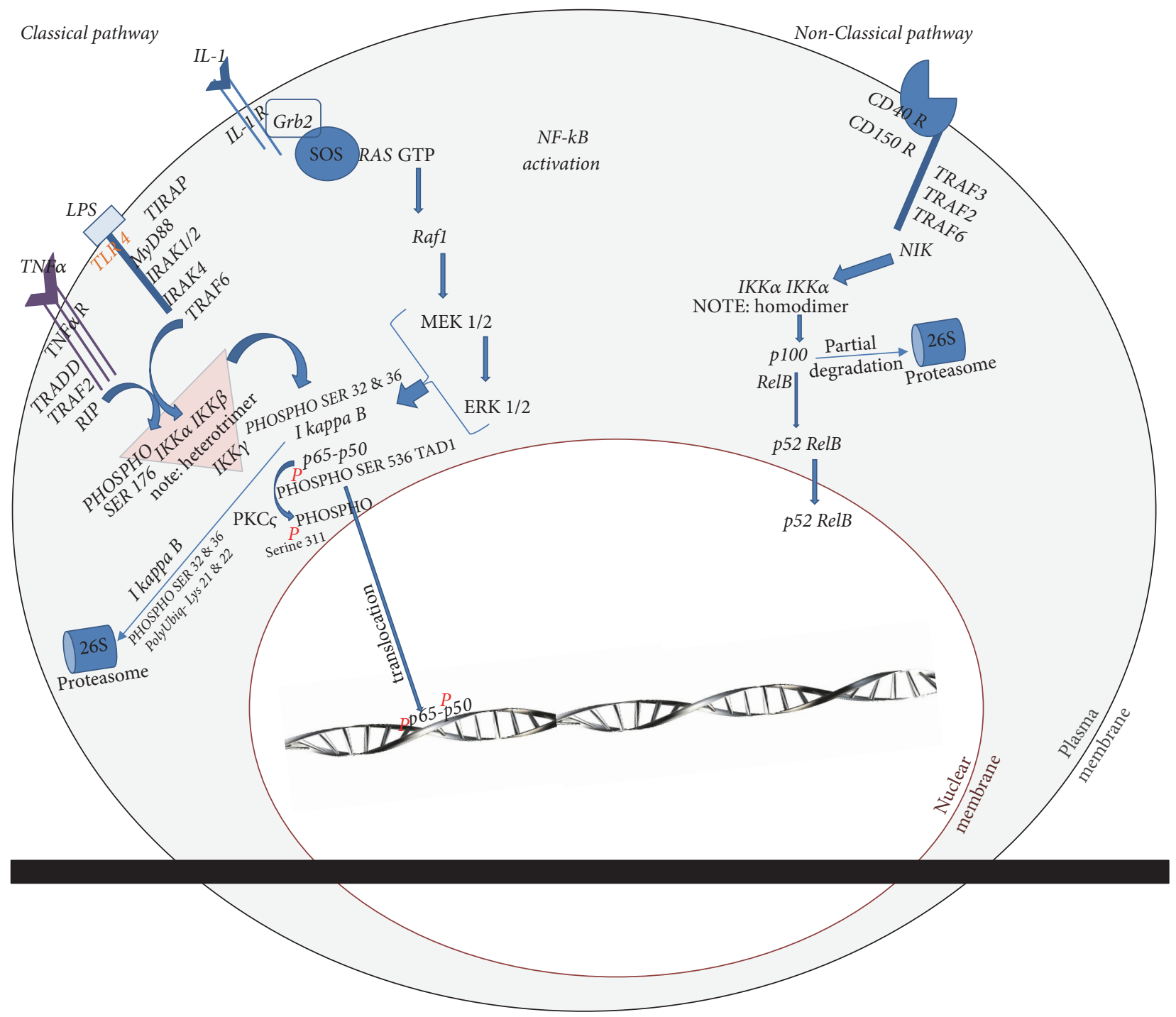

Figure 2: Depiction of classical and nonclassical pathway to NF-kB (p65-p50 or RelBp52) translocation activation. Figure: schematic by Franco Cavaleri.

activity [51, 71]. Otherwise, the NF-kB p65-p50 heterodimer is held inactive in the cytoplasm by the I-kappa-B repressor protein until I-kappa-B is phosphorylated by I-kappa-B kinase (IKK) at serines ${ }^{32 \& 36}$ to set in motion its degradation by the $26 \mathrm{~S}$ proteasome [72].

A rather simplistic model explaining the activation of the cytoplasmic p65-p50 heterodimer speaks to IKK activation by phosphorylation of its serine ${ }^{176}$ [73]. This IKK phosphorylation can be induced by a variety of upstream kinases as shown in Figure 2 and once phosphorylated it ultimately frees the heterodimer to facilitate p65-p50 translocation into the nucleus. The IKK complex is typically found as a heterotrimer in the cytoplasm as shown in Figure 2 or as a homodimer [74, 75 ] as seen in the alternate nonclassical transduction pathway of the same figure. These aggregated IKK isoforms crossphosphorylate or crosstalk to facilitate their synergistic roles $[76,77]$. The variable IKK configurations trigger different modalities by which free p65-p50 or p65-p52 transcription factors are, respectively, generated from different upstream receptors to make for varying translocation dynamics and transcriptional outcomes by the same family of transcription factors. It is a nonlinear, rather complex, system producing outcomes that can vary rheostatically and by gene target $[23,78]$.

Once uncoupled from its cytosolic repressor, p65-p50 can translocate into the nucleus [79] to engage in the transcription of genes with the kappa-B motif (GGG ACT TTC C) $[58,80]$. This promoter nucleotide motif is essential for NF$\mathrm{kB}$ docking. While posttranslational phosphorylation of $\mathrm{p} 65$ may be required for docking and expression of one gene, other posttranslational modifications of the transcription factor can prevent its docking on gene promoters [81-84] and transactivation despite the promoter regions of these genes containing the requisite kappa-B nucleotide motif. This phosphorylative coding helps shape p65-p50 transactivation selectivity after the transcription factor has translocated into 


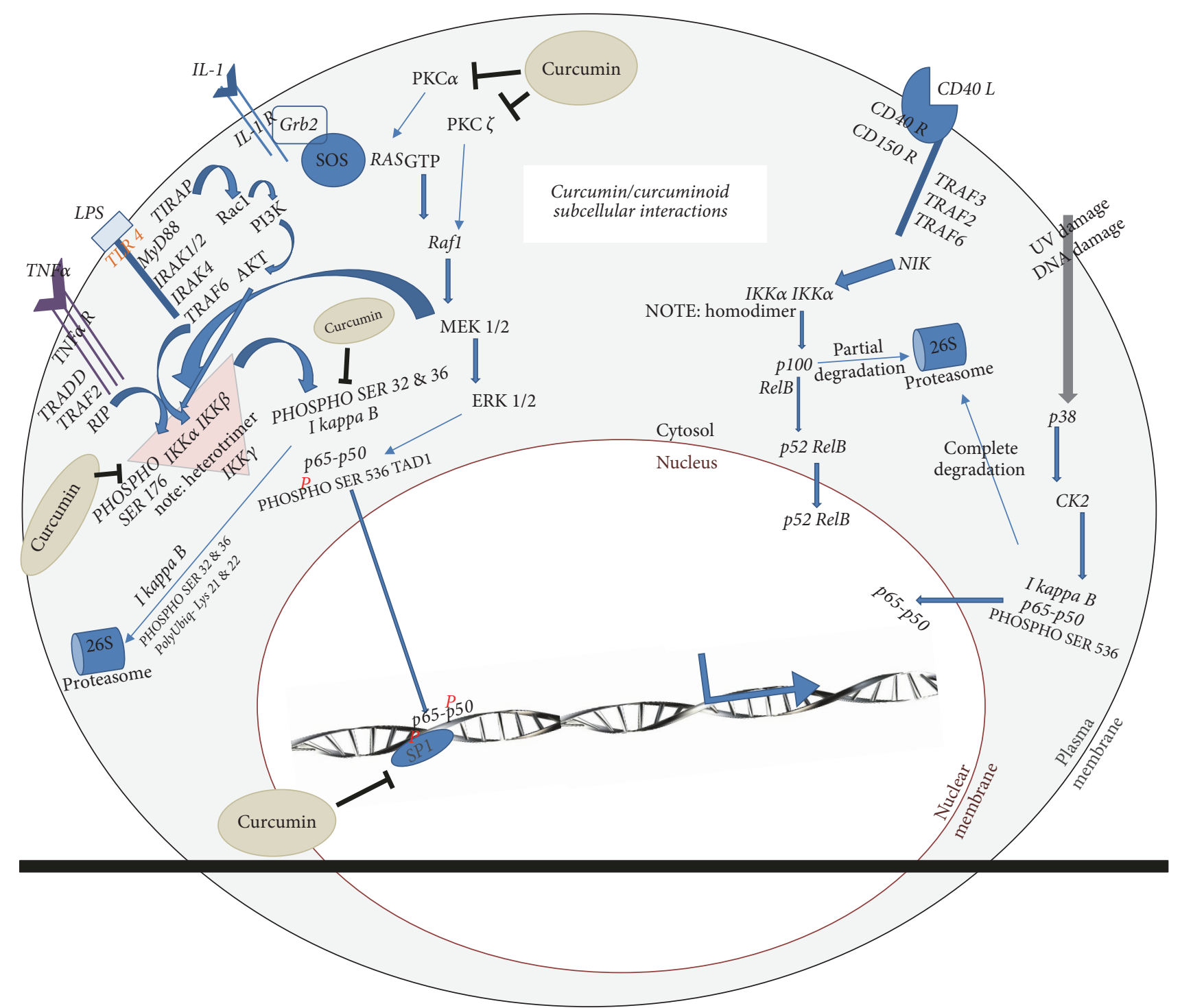

FIGURE 3: Curcumin polypharmacology plotted to show a rendered influence on p65-p50 transactivation potential showing a relatively more selective outcome if NF-kB is selected as the ultimate target of the polypharmacology.

the nucleus $[83,85]$ guiding it to highly specific genomic targets [86-88]. Despite the fact that the transcription factor potentially expresses as many as 150 different genes this phosphorylative coding, as will be further detailed, limits transactivation to the expression of genes which produce an appropriately measured behavioural response to the stimulus that started in motion the NF-kB activity [89-93].

Despite translocation, phosphorylation of the right p65 amino acid residues, and accessibility to a kappa-B equipped gene promotor, transcription by p65-p50 of the kappa-B TATA-less promoter also depends on the activation by phosphorylation of other nuclear transcription factors such as Sp1 $[94,95]$ and cAMP response element binding protein (CREB) [96]. The TATA box (consensus sequence TATAAAA) is located upstream of the start site of transcription and serves as a facilitator for transcription factor-promoter binding in higher eukaryotes [97]. The kappa-B promoter for which the p65-p50 transcription factor has affinity is TATA-less with the TATA region replaced by a "CG-rich" nucleotide sequence.

As a function of the TATA-less configuration, transcription by NF-kB depends on cotranscription factors that converge on the promoter to facilitate NF-kB docking and gene expression [98]. In the case of p65-p50, we see cotranscription factors Sp1 and CREB serving this purpose [94, 95]. Gene expression naturally also depends on histone phosphorylation and acetylation of chromatin to induce remodelling and accessibility by these converging cotranscriptional elements [96, 99-101]. Further to the old school understanding of IKK's cytosolic activation of p65-p50, once phosphorylated, IKK is more recently known to shuttle into the nucleus [99] and also partake in histone $\mathrm{H} 3$ phosphorylation which supports chromatin remodelling [102]. The shaping and regulation of NF-kB are complex and comprehensive to say the least but this complexity produces an opportunity for multiple 
points of regulation that we will see shortly. Curcumin is intimately interactive with and regulatory of this NF-kB signalling pathway at multiple points $[23,103,104]$. Figure 3 captures this interactive dynamic in schematic form.

\section{MAPK Pathway Crosstalk with NF-kB Signalling Pathway}

The MAPK pathway is also involved in this NF-kB shaping [105]. The MAPK pathway is an evolutionary ancient pathway like NF-kB's and is found in most species to control a vast array of cellular processes [106]. Curcumin is closely interactive with and regulatory of the MAPK pathway as well $[107,108]$. This pathway interacts intimately with NF-kB [105, 109]. The MAPK pathway, like the NF-kB proteins and their pathways, is activated by inflammatory cytokines [110] and by environmental stressors to contribute to disease pathologies from tumorigenesis [111] to autoimmune diseases [112] and asthma $[113,114]$. This central pathway plays a critical role in cell survival, apoptosis, and proliferation [115, 116]. NF-kB p65 (RelA) protein shaping by phosphorylation is complex [117-119] and begins in the cytoplasm, in part, by the MAPK (MEK/ERK) and continues into the nucleus all the way to transactivation and expression of the transcription factor's cognate genes $[90,105,109,120-123]$ as seen in Figures 2 and 3.

As previously discussed, phosphorylation of various p65 residues affords the NF-kB transcription factor the phosphorylative coding required to dock on some promoters for transactivation and not others once it has translocated. For example, phosphorylation of p65 serine $\mathrm{e}^{536}$ is expected to be necessary for nuclear translocation but is also required for transcription of IL-6 [85]. However, lack of p65 serine ${ }^{536}$ phosphorylation abrogates p65 affinity for the IL-8 gene promotor [83]. Lack of serine ${ }^{536}$ phosphorylation does not, however, preclude the p65 heterodimer from docking and transcribing other cytokines, the genes of which are equipped with the kappa-B nucleotide motif.

Nuclear phosphorylation of the NF-kB p65 protein continues to shape the transcription factor's activity through nuclear kinases like the MAPK mitogen- and stress-activated kinase 1 (MSK1) $[124,125]$. MSK1's nuclear activity is multifactorial and compounding in the context of $\mathrm{NF}-\mathrm{kB}$ regulation. It phosphorylates and activates CREB [126], one of the p65p50's cotranscription factors. In addition to MSK1, protein kinase A (PKA) [50, 125] coordinates a symphony of nuclear events that aggregate multiple cotranscription factors as well, including phosphorylation and activation of CREB [126] just like MSK1 does [105, 127]; activation of CBP/p300 and $\mathrm{Sp} 1$; and coordination of HDAC-1 to further contribute to chromatin remodelling [50]. These transcriptional elements all converge on and collaborate toward regulation of p65-p50 transactivation.

Both MAPK and NF-kB pathways are central to disease pathology and cell survival [115, 128-130]. Curcumin targets both these pathways at multiple points each as previously cited, portrayed schematically in Figure 2 [131-133], and discussed further in the pages to come.

\section{Curcumin Helps Shape NF-kB p65-p50 Transactivation and Inflammation}

Regulation of the NF-kB transcription factor is rather complex and the result of its modification can have profound implications based on the plethora of genes it transcribes [6062]. To know that curcumin can inhibit p65-p50 activity at multiple phosphorylation sites sets the stage for an interesting investigative journey. However, to consider that the naturally occurring curcuminoid analogues comprising the curcumin extract have differing structural features that may be contributing different pharmacological characteristics leads to the cautious expectation that the true pharmacology of the curcumin extract has yet to be demystified.

The complexity of the subcellular events induced by curcuminoid preparations in various studies indicates that the curcuminoids are aimed at multiple biological targets where many of which guide NF-kB p65-p50 transactivation [23, 131, 134]. The effective inhibition of p65-p50 and inflammation by curcumin [135] heightens interest in the natural extract as a therapeutic agent [136]. However, curcumin pharmacology may be as complex and convoluted as the pleiotropic activity of the NF-kB family of transcription proteins. Curcumin is shown to inhibit IKK [23] as one component of the natural extract's pharmacology and as a result curcumin ultimately inhibits p65-p50 nuclear translocation [137, 138]. Curcumin inhibition of IKK is a classically accepted mechanism for the natural extract's anti-inflammatory activity [23, 138]. However, this cannot completely explain all the pharmacological outcomes shown in the literature with curcumin treatment [139]. Curcumin is shown to also inhibit PKC [140], which inhibits MAPK activity. Curcumin is also shown to inhibit Raf-1 $[132,133]$ which also reduces MEK signalling (MAPK) from yet another point in the MAPK pathway as seen in Figures 2 and 3. Inhibition of multiple cytosolic PKC isoforms [103, 140-142] plays a monumental role in MAPK pathway regulation $[143,144]$.

The symphony of curcuminoid activity on transduction through the MAPK pathway modulation and influences of NF-kB transactivation appears at first to be void of selectivity or strategy. However, once this plethora of activity is carefully mapped, a bigger picture begins to emerge. The pleiotropic influences by curcumin and its inherent curcuminoid analogues seem to be honing in, in a compounding manner, on inhibition of p65 activity. The extract's polypharmacology looks as though it is sharpening transactivation of p65p50 synergistically through crosstalk by the MAPK pathway all the way into the nucleus. As mentioned, curcumin is also shown in the literature to inhibit PKA [145] delivering another level of compounding inhibitive activity on p65-p50 transactivation at the nuclear level.

Curcumin's pharmacology is complex. Curcumin is shown to inhibit transactivation of p65-p50 while still maintaining basal activity in healthy cells [146]. Curcumin is shown to induce apoptosis in mutated cells such as melanoma $[146,147]$ and to facilitate apoptosis by chemotherapies in drug-resistant cells improving drug efficacy [148]. This could be intimately related to its influence on NF-kB. Curcumin enhances caspase 8 activity [149]. However, at the same time, 
curcumin promotes malignant cell death and it preserves and protects healthy cells in the same environment from chemotoxicity [148]. Curcumin's pharmacology varies depending on cell type and receptor-ligand interaction triggering the cell response [150-152]. Different sources of cell stimulation such as LPS, TNF $\alpha$, and TGF $\beta$, to name a few, which initiate transduction from different receptor sites create a differential p65 phosphorylation dynamic $[129,153]$.

The variable trigger points for inflammatory activity result in variations of the same p65 protein [85] that differ in their phosphorylation and heterodimer configurations; the outcome of which is multiple condition-specific responses from one transcription factor. Nevertheless, curcumin inhibits the different IKK isoforms involved in these different pathways and the different NF-kB heterodimer configurations that rise out of these different trigger points $[23,154,155]$. Still, despite all we know about the many mechanisms involved, the fundamental mechanism driving curcumin pharmacology is not fully understood since we are still discovering new targets and new interactions with conflicting results [156-160].

By modulating brain derived neurotrophic factor (BDNF) [161], curcumin performs as an antidepressant agent in a fashion similar to fluoxetine and imipramine [162]. Curcumin is shown to improve cardiac hypertrophy and heart failure in animal models $[163,164]$. Curcumin can perform better than diclofenac sodium in the treatment of rheumatoid arthritis $[6,165]$. In murine models of cystic fibrosis (CF), curcumin improves cystic fibrosis transmembrane conductance (CTFR) defects [166]. The extract helps improve muscle regeneration after injury [167]. Administration of curcumin improves cognitive function in Alzheimer's disease patients [168] and improves COPD-like airway inflammation [169]. Curcumin administration improves lipid metabolism to support healthier total cholesterol and HDL to LDL ratios associated with obesity [170-172].

However, as much as these and many other positive findings serve as a storyline for curcumin praise just as many studies demonstrate lack of efficacy with curcumin administration [173]; in depression models [174]; in CTFR (CF) defects [175]; and in rheumatoid arthritis and inflammatory bowel disease [176]. There is no doubt that curcumin can play a role in the management of inflammatory disease but in order for this to happen with greater reliability, the underlying mechanism must be better understood.

Curcumin has shown promise in the treatment of cancer [177], for instance, and in combination with paclitaxel can be effective in enhancing cytotoxicity in drug-resistant cancers [178-180]. Although the mechanism is understood to be centered on NF-kB inhibition by curcumin, the full story is still incomplete.

\section{Curcumin-Based Therapy Challenges}

A new perspective that involves two new viewpoints must be adopted in order to unveil some of the mystery still trapped within this natural extract.

Studying each of the curcuminoid analogues in isolation may help unravel some of the mystery surrounding this medicinal agent. Synthetic curcumin analogues, for example, can display unique pharmacological characteristics associated with structure [181, 182], structural differences that are rather miniscule. The naturally occurring curcuminoid analogues display similar structural characteristics, but as shown in Figure 1, their unique features may also contribute distinct pharmacological characteristics that are unique to each analogue. However, the naturally occurring curcuminoid analogues have not been studied expansively in this context in the past. A reevaluation of each of the curcuminoid analogues' pharmacology in isolation in the framework of NF-kB regulation may provide more insight into the full spectrum of curcumin activity and the source of the curcumin extract's polypharmacology.

Curcuminoid nomenclature also needs to be revisited. The whole 1:1 turmeric rhizome powder (Curcuma longa) will contain approximately $3-6 \%$ curcumin that comprises a mixture of the three naturally occurring curcuminoid analogues at concentrations that approximate $50-80 \%$ curcumin I, 10-20\% curcumin II, and $0.5-2 \%$ curcumin III [31, 183-185]. Total curcumin content can be as high as $98 \%$ for a curcumin extract that retains these same curcuminoid analogue proportions inherently [139]. The term "curcumin" can refer to the principal curcuminoid, curcumin I (one), also called diferuloylmethane [186]. However, the term "curcumin" is confusingly also used in the literature and commercial applications, as will be shown, to describe the curcumin extract that contains all three curcuminoids (I, II, and III). To make matters related to consistency worse, the proportion of the naturally occurring curcuminoid analogues (I, II, and III) in curcumin extracts can vary from sample to sample contributing to a lack of standardization when comparing research executed with "curcumin." This lack of nomenclature clarity must be more definitive.

Natural curcumin preparations that are standardized to a precise concentration, often as high as 95\% curcumin, have within them these underlying variances that may be contributing to inconsistent outcomes. The assumption is that the curcuminoid analogues all display similar pharmacology. However, studies do point to the likelihood that the curcuminoids do not produce the same pharmacology on all targets. For example, bisdemethoxycurcumin (curcumin III aka BDMC) is shown to deliver cytotoxicity to inhibit growth of the K562 cell line and this inhibitory activity is significantly greater than that of curcumin (curcumin I aka diferuloylmethane) and demethoxycurcumin (curcumin II aka DMC) [187]. On the other end of the spectrum studies showed that curcumin I and demethoxycurcumin (curcumin II) have equally potent inhibitory activity on TPA induced tumorigenesis but bisdemethoxycurcumin (curcumin III) was less active [188]. The mechanisms are undefined and seemingly conflictive, nevertheless indicative of different activity by the different curcuminoid analogues.

The curcumin nomenclature does not help to make research initiatives clear. If we take an example of PKC inhibition by curcumin [189], Balasubramanyam et al. revealed that they acquired their curcumin for research from SigmaAldrich Co. with no more descriptive detail in the study. Another study demonstrating PKC inhibition by curcumin 
<smiles>COc1cc(/C=C/C(=O)CC(=O)/C=C/c2ccc(O)c(OC)c2)ccc1O</smiles>

Curcumin I
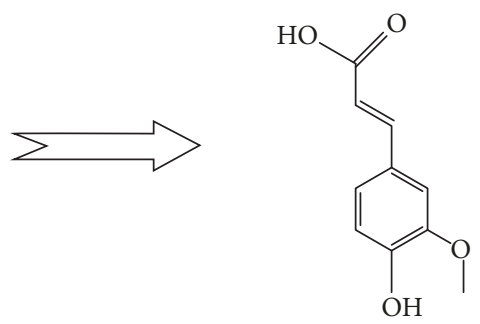

Ferulic acid

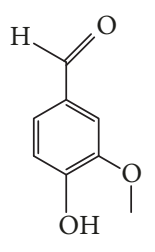

Vanillin

FIGURE 4: Diferuloylmethane's (curcumin I) nonenzymatic degradation yielding ferulic acid and vanillin as by-products.

[103] where curcumin is "purchased from LKT Laboratories (>98\%)" includes no more detail than this in the material description including no catalogue number for the item. Upon viewing the LKT catalogue, it is confirmed that this product appears to be almost exclusively curcumin I. Other researches showing that curcumin inhibits PKC $[190,191]$ simply state that curcumin is procured from Sigma and no more detail other than that.

Sigma, in another example, displays a $94 \%$ curcuminoid content curcumin (catalogue number C7727) but guarantees greater than $80 \%$ curcumin in the research standard. This product is obviously a curcumin extract, labelled "curcumin" but supplies multiple curcuminoids with the major curcuminoid analogue being curcumin I based on the molecular structure of the primary constituent shown in the product specification sheet. However, this product is more than just curcumin I; it also includes a nondescript array of other curcuminoids and as a result provides a variety of possible contributors to the pharmacology demonstrated in the study.

Inhibition of PKC by curcumin is shown in another study by Mahmmoud [192]. They too are using Sigma's curcumin (catalogue number C7727) which contains more than one curcuminoid analogue but the researchers refer to their inhibitor as "curcumin." Catalogue number C7727 has only approximately $80 \%$ curcumin I and almost $20 \%$ other constituents. Inconsistent material specification may be playing a monumental role in the lack of reliability and repeatability of research and treatment outcomes. As we have demonstrated above, the curcuminoid analogues can display differing pharmacology and as submitted, standardization must be taken more seriously.

Acknowledging the Pharmacological Contribution of the Curcumin Autooxidative By-Product. High dose administration by oral route of some curcumin products results in limited to no serum curcumin in the subjects [24, 193], so why therapeutic results are still positive? Curcumin readily degrades in biological mediums and biological $\mathrm{pH}$ nonenzymatically to yield ferulic aldehyde, trans-6-(40-hydroxy30-methoxyphenyl)-2,4-dioxo-5-hexenal, feruloyl methane, ferulic acid, and vanillin [194]. Although the studies have revealed conflictive evidence, some of these degradation byproducts display significant pharmacological activity [195197]. In addition, some, such as ferulic acid and vanillin, unlike the parent curcuminoids, display significant solubility and stability in biological mediums and at biological $\mathrm{pH}$
$[198,199]$. If serum curcumin levels are regularly measured too low $[24,193]$ to account for pharmacological results after steady oral loading with curcumin, what is the source of the irrefutable results [200]? Are the nonenzymatic autooxidative degradation products responsible?

Curcuminoid degradation proceeds rapidly at $\mathrm{pH}$ above neutral, which is associated with biological mediums [198, 201]. Is curcumin or its degradation by-products responsible for the in vivo pharmacology at the site of activity? Are both classes, degradation and parent molecules, responsible? While curcumin is known to inhibit xanthine oxidase [202], ferulic acid, for example, a curcumin degradation by-product is also shown to inhibit xanthine oxidase reducing uric acid crystallization associated with gout [203-205]. Inhibition of xanthine oxidase can also reduce the intensity of many symptoms of disease including nonspecific symptoms associated with aging and chronic inflammation [206]. Xanthine oxidase escalates superoxide radical production, where overactivity simply produces additive biological stress [207]. Inhibition may play a functional role in disease management.

Ferulic acid administration can facilitate NO-mediated vasodilation [208]; pharmacology is also induced by curcumin administration [209]. Curcumin [210], just like ferulic acid [211], is shown to have significant antitumor activity. While we know that curcumin inhibits NF-kB $[155,212]$, ferulic acid is shown to do the same [213]. Curcumin [155, 212, 214-217], just like ferulic acid [197, 217-219], destabilizes preformed $\beta$-amyloid protein and inhibits stability of soluble oligomer and fibril aggregation. Vanillin, a curcumin degradation by-product, inhibits cyclooxygenase (COX), NF$\mathrm{kB}$, caspase-1 [220], and ischemia-induced hippocampal CA1 cell death [221]. Vanillin also protects neurons from oxidative stress [197].

Since oral administration of some curcumin drugs is shown to result in low to zero serum curcumin even with prolonged high dose administration [18, 222], it leaves us with the degradation products as likely contributors, at least in part, to the broad polypharmacology attributed to curcumin. However, not all curcumin-related studies reflect the same curcumin bioavailability limitation so inevitably serum curcuminoids are playing a significant role as will be evidenced shortly. It must be considered that this autooxidative degradation of curcumin may not proceed as linearly as we would like to think. Figure 4 displays the nonenzymatic degradation products of diferuloylmethane's (curcumin I) depicted again with ferulic acid and vanillin as by-products. 
<smiles>O=C(/C=C/c1ccc(O)cc1)CC(=O)/C=C/c1ccc(O)cc1</smiles>

Curcumin III
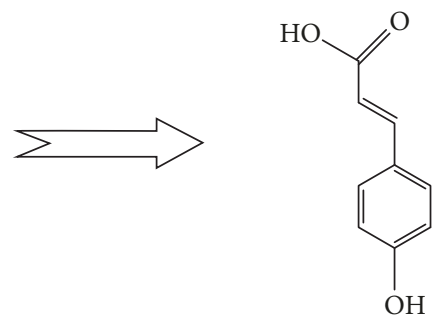

Ferulic acid

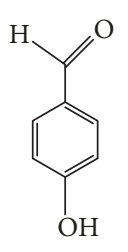

Vanillin

Variants

FIGURE 5: Bisdesmethoxycurcumin's (curcumin III) nonenzymatic degradation yield.

However, curcumin III (bisdemethoxycurcumin) would produce degradation products with structure varying from those presented for curcumin I as seen in Figure 5.

In addition to the nonenzymatic autooxidative degradation of curcumin, curcumin is quickly metabolised enzymatically in an attempt by the body to neutralize and eliminate the natural agent. This enzymatic modulation starts in the intestinal lumen $[223,224]$ and subsequently, once absorbed into systemic circulation, yet another therapeutic barrier, the liver, imposes enzymatic neutralization. The metabolites resulting from this activity are quickly further subjected to glucuronation and sulfation to form curcumin glucuronide, curcumin sulfate, dihdrocurcumin glucuroside, tetrahydrocurcumin glucuronoside, and hexahydrocurcumin glucuronoside [223, 225-227]. This enzymatic neutralization contributes further to the elimination of serum curcumin and that low to no serum curcumin often associated with curcumin administration even at high oral doses. However, despite the apparent limitations associated with bioavailability, oxidative degradation and metabolic activity in vivo results persist albeit not reliably by all curcumin-containing products tested [216, 228-231, 231-233].

\section{The Therapeutic Value of a Standardized Curcuminoid Treatment}

Needless to say, curcumin's potential as a therapeutic agent is significant. However, there are some challenges that need to be overcome. Curcumin is known for its bioavailability limitations but this challenge may very well be overstated. Contrary to the stated bioavailability limitations, many studies such as that executed by Baum et al. applying regular curcumin extract in human clinical trials at daily doses of 1.0 grams showed significant serum curcumin $(1100+/-260 \mathrm{nM})$ within 1.5 hours [234]. In addition, the parent curcuminoids were also accompanied by significant serum levels of the nonenzymatic degradation by-products of curcumin. Poor curcumin/curcuminoid bioavailability is said to be caused by the phenolic compound's hydrophobic property and the consequential poor solubility in aqueous mediums [235].

Improving curcumin solubility in aqueous medium by complexing the curcuminoid with hydrophilic compounds like phosphatidylcholine improves solubility but is also purported to improve bioavailability [200]. However, these studies showing increased serum curcumin with reacted forms of curcumin that appear to have higher solubility [200] in aqueous solutions than curcumin alone might be missing another cause of improved serum curcumin, such as improved survival against hepatic enzyme modification [236]. In addition, improved solubility does not convey improved bioavailability. Even in studies that show low to no serum curcumin upon oral administration [24, 37, 193, 237] and excessive efflux [238] reported results from the therapies as previously mentioned are considered good, thus indicating from this standpoint that other factors, possibly even the autooxidative degradation by-products, are contributing pharmacology.

Regulation of the complex NF-kB transcription factor can play a significant role in disease management and improved cell survival $[153,239,240]$. Curcumin's biological activity is intimately interactive with NF-kB through multiple targets to downregulate the transcription factor and its involvement in disease pathology $[23,23,155,182]$. Since inflammatory chemistry is central to all disease pathology in one form or another and is ultimately the target of disease treatment including diseases as difficult to treat as cancer [241-243], multiple sclerosis [244, 245], rheumatoid arthritis [245-247], ulcerative colitis [248, 249], Crohn's disease [250], and other autoimmune and autoinflammatory diseases [251, 252], NF$\mathrm{kB}$ regulation is a highly targeted prospect in disease therapy [253].

Improved regulation of inflammatory markers by curcumin administration can lead to the potential improvement cognitive deficits [254], those aligned with Parkinson's disease pathology [255], Alzheimer's disease [168], and nonspecific oxidative brain damage [256, 257]. Obesity, as we have seen, is also closely linked with inflammation [47-49]. These age- and lifestyle-related diseases are North American epidemics today evolving to global pandemic status [258260]. The right curcuminoid design could play a powerful therapeutic role in the treatment or prevention of many diseases including premature aging.

\section{Future Direction for Curcumin Standardization in Research and Therapy}

The future of curcumin is as bright as its pigmentation. However, in order for the pharmacology of this medicinal agent to be optimised, a better understanding of the distinct 
pharmacology of each naturally occurring curcuminoid analogue must be fully explored. The expansive polypharmacology is likely a function of the multiple targets successfully modulated by each curcuminoid analogue distinctly and the same targets they may successfully regulate to produce additive activity. In addition, it may be considered that the curcuminoid analogues successfully modulate distinct targets that act synergistically by crosstalk such as that seen between the MAPK and NF-kB pathways. In all, the total outcome of this polypharmacology may be one that plays out as a strategic corralling or shaping of NF-kB transactivation as described schematically in Figures 2 and 3.

Curcumin must be studied from this polypharmacological point of view in order to better understand the pharmacokinetics and pharmacology of each curcuminoid in isolation. This compartmentalized information will likely help us improve selective usage of curcumin-based strategies in research. It may even help improve the synergistic value hiding within the natural extract that may be unlocked by man-made drug designs that involve varying the curcuminoid analogue proportions within the curcumin-based treatment.

It is well established in some studies that bioavailability limitations are real with the hydrophobic curcumin but this is countered by studies that show otherwise. Commercially driven claims that the hydrophobic nature of the curcuminoid and its lack of solubility in aqueous mediums is the cause of curcumin bioavailability limitation is simply unfounded. Even with those demonstrating poor serum curcumin after heavy oral dosing, there is difficulty explaining the pharmacological results experienced by subjects receiving curcumin.

Serum curcumin levels are not found to be significant enough to explain therapeutic results in some studies [24, $37,193,223,224]$ but as has been demonstrated in other researches, serum curcumin with unmodified curcumin extracts that are properly extracted can be significant and sufficient for efficacy [200]. However, despite the challenges, in vivo results can range from therapeutically great to mediocre from one curcumin-based product to another [216, 228-231, 231-233]. This indicates that other factors are playing pharmacological roles and also contributing activity. It is likely the internal proportion shifts of the curcuminoid analogues and the autooxidative by-products that must be considered in this pharmacological equation. The inconsistency and uncertainty are amongst the challenges that researchers need to overcome in order for the true value and full potential of this therapeutic agent to be extracted and put to good use.

Despite some attempts to improve curcumin bioavailability through liposomal and other forms of microencapsulation [261-263] and aerosol delivery [264], the effective hepatic degradation of the curcuminoids [223, 225-227] and that which can start in the lumen $[265,266]$ are shown to present yet another formidable therapeutic barrier contributing to serum insufficiency found with curcumin dosing. The conditions in which the curcumin-based therapies are studied also play a monumental role in the outcome seen in the literature. Serum proteins significantly improve curcumin survival [194] so once in the bloodstream a unique dynamic ensues. Factors such as $\mathrm{pH}$, serum antioxidant status, and temperature all influence curcuminoid stability and autooxidative degradation [194, 267].

The status of the by-products of curcumin autooxidative degradation and their potential contribution to in vivo pharmacology must also be studied with greater sophistication such as starting with fundamental measurement of actual tissue distribution. Too much conflicting data has been presented in this context [38, 194, 268-270] and although the multiple viewpoints are great to see for meta-analysis, it must be considered that these conflicting positions could also be a function of the variable conditions being used to study the curcuminoids. Variable $\mathrm{pH}$, temperature, serum protein, and other conditions, if even mildly varied, result in varying the degradation dynamic and outcome even at the analytical stage of serum samples after extraction.

Standardization of the curcumin extract to clearly define its constituent curcuminoid analogues at every juncture is crucial. Labelling and definitions of standards and consumer products must be made more universal. Curcumin extracts described on the label of a supplement source or natural therapeutic product, for example, may not be describing the same principal agent today from brand to brand due to these discrepancies in interpretation. Even within one brand, however, the variable proportion of curcuminoid analogues could also play a role in the inconsistency experienced from one lot number to the next using the existing regulatory standards. An extract displaying 95\% curcumin purity, for instance, does not necessarily specify the curcuminoid proportions (I, II, and III). This lack of consistency extends to the peer-reviewed literature as well.

"Curcumin" is a descriptor often used to describe the curcumin extract which contains all three curcuminoids: curcumin I, curcumin II, and curcumin III. Confusingly, however, as described, "curcumin" is also used to describe curcumin I on a label. It must be established as a standard in commercial and research applications that a reference made to any one or three of the curcuminoids would be qualified by naming the specific curcuminoids. This nomenclature specificity must be standardized globally in order for label claims on consumable products, pharmacological agents, and research reports to be consistent in the health care field including peer-reviewed literature. Once this standard is set and adhered to we can begin to further define and better understand the expansive potential of this therapeutic agent with reliable and repeatable results.

\section{Conflicts of Interest}

The author is the owner of a corporation that funds and executes research on nutraceutical pharmacology and experimental medicine and has been involved in the research of curcuminoids and other isolated botanical agents.

\section{Acknowledgments}

Special thanks are due to the author's colleague and good friend Emran Bashar for proof and edit support. 


\section{References}

[1] R. F. Tayyem, D. D. Heath, W. K. Al-Delaimy, and C. L. Rock, "Curcumin content of turmeric and curry powders," Nutrition and Cancer, vol. 55, no. 2, pp. 126-131, 2006.

[2] D. Heath, F. Khwaja, and C. Rock, "Curcumin content of turmeric and curry powders," Faseb Journal, 2004.

[3] A. Kerkeni, N. Behary, A. Perwuelz, and D. Gupta, "Dyeing of woven polyester fabric with curcumin: Effect of dye concentrations and surface pre-activation using air atmospheric plasma and ultraviolet excimer treatment," Coloration Technology, vol. 128, no. 3, pp. 223-229, 2012.

[4] M. T. Huang, Y. R. Lou, W. Ma, H. L. Newmark, K. R. Reuhl, and A. H. Conney, "Inhibitory effects of dietary curcumin on forestomach, duodenal, and colon carcinogenesis in mice," Cancer Research, vol. 54, no. 22, pp. 5841-5847, 1994.

[5] M. Sinha et al., "Study of the mechanism of action of curcumin: an antiulcer agent," 1975.

[6] B. Chandran and A. Goel, "A randomized, pilot study to assess the efficacy and safety of curcumin in patients with active rheumatoid arthritis," Phytotherapy Research, vol. 26, no. 11, pp. 1719-1725, 2012.

[7] T. N. Patil and M. Srinivasan, "Hypocholesteremic effect of curcumin in induced hypercholesteremic rats.," Indian Journal of Experimental Biology (IJEB), vol. 9, no. 2, pp. 167-169, 1971.

[8] M. D. Laird, S. Sukumari-Ramesh, A. E. B. Swift, S. E. Meiler, J. R. Vender, and K. M. Dhandapani, "Curcumin attenuates cerebral edema following traumatic brain injury in mice: a possible role for aquaporin-4?" Journal of Neurochemistry, vol. 113, no. 3, pp. 637-648, 2010.

[9] I. Chattopadhyay, K. Biswas, U. Bandyopadhyay, and R. K. Banerjee, "Turmeric and curcumin: biological actions and medicinal applications," Current Science, vol. 87, no. 1, pp. 44-53, 2004.

[10] C. Elder, "TITLE: Ayurveda for diabetes mellitus: a review of the biomedical literature," Alternative Therapies in Health and Medicine, vol. 10, no. 1, pp. 44-50, 2004.

[11] K. C. Srivastava, A. Bordia, and S. K. Verma, "Curcumin, a major component of food spice turmeric (Curcuma longa) inhibits aggregation and alters eicosanoid metabolism in human blood platelets," Prostaglandins, Leukotrienes and Essential Fatty Acids, vol. 52, no. 4, pp. 223-227, 1995.

[12] C. Tohda, N. Nakayama, F. Hatanaka, and K. Komatsu, "Comparison of anti-inflammatory activities of six Curcuma rhizomes: a possible curcuminoid-independent pathway mediated by Curcuma phaeocaulis extract," Evidence-Based Complementary and Alternative Medicine, vol. 3, no. 2, pp. 255-260, 2006.

[13] H. H. P. Cohly, A. Taylor, M. F. Angel, and A. K. Salahudeen, "Effect of turmeric, turmerin and curcumin on $\mathrm{H} 2 \mathrm{O} 2$-induced renal epithelial (LLC-PK1) cell injury," Free Radical Biology \& Medicine, vol. 24, no. 1, pp. 49-54, 1998.

[14] L. Srinivas, V. K. Shalini, and M. Shylaja, "Turmerin: A water soluble antioxidant peptide from turmeric [Curcuma longa]," Archives of Biochemistry and Biophysics, vol. 292, no. 2, pp. 617623, 1992.

[15] P. S. Negi, G. K. Jayaprakasha, L. Jagan Mohan Rao, and K. K. Sakariah, "Antibacterial activity of turmeric oil: a byproduct from curcumin manufacture," Journal of Agricultural and Food Chemistry, vol. 47, no. 10, pp. 4297-4300, 1999.

[16] B. T. Kurien and R. H. Scofield, "Increasing aqueous solubility of curcumin for improving bioavailability," Drug Metabolism \& Disposition, vol. 36, pp. 1594-1605, 2009.
[17] R. L. Thangapazham, A. Sharma, and R. K. Maheshwari, "Multiple molecular targets in cancer chemoprevention by curcumin," The AAPS Journal, vol. 8, no. 3, pp. E443-E449, 2006.

[18] R. A. Sharma, A. J. Gescher, and W. P. Steward, "Curcumin: the story so far," European Journal of Cancer, vol. 41, no. 13, pp. 19551968, 2005.

[19] F. Payton, P. Sandusky, and W. L. Alworth, "NMR study of the solution structure of curcumin," Journal of Natural Products, vol. 70, no. 2, pp. 143-146, 2007.

[20] A. Shehzad, F. Wahid, and Y. S. Lee, "Curcumin in cancer chemoprevention: Molecular targets, pharmacokinetics, bioavailability, and clinical trials," Archiv der Pharmazie, vol. 343, no. 9, pp. 489-499, 2010.

[21] R. K. Maheshwari, A. K. Singh, J. Gaddipati, and R. C. Srimal, "Multiple biological activities of curcumin: a short review," Life Sciences, vol. 78, no. 18, pp. 2081-2087, 2006.

[22] M. Li, Z. Zhang, D. L. Hill, H. Wang, and R. Zhang, "Curcumin, a dietary component, has anticancer, chemosensitization, and radiosensitization effects by down-regulating the MDM2 oncogene through the PI3K/mTOR/ETS2 pathway," Cancer Research, vol. 67, no. 5, pp. 1988-1996, 2007.

[23] S. M. Plummer, K. A. Holloway, M. M. Manson et al., "Inhibition of cyclo-oxygenase 2 expression in colon cells by the chemopreventive agent curcumin involves inhibition of NF- $\kappa \mathrm{B}$ activation via the NIK/IKK signalling complex," Oncogene, vol. 18, no. 44, pp. 6013-6020, 1999.

[24] N. Dhillon, B. B. Aggarwal, R. A. Newman et al., "Phase II trial of curcumin in patients with advanced pancreatic cancer," Clinical Cancer Research, vol. 14, no. 14, pp. 4491-4499, 2008.

[25] J. S. Jurenka, "Anti-inflammatory properties of curcumin, a major constituent of Curcuma longa: a review of preclinical and clinical research," Alternative Medicine Review, vol. 14, no. 2, pp. 141-153, 2009.

[26] X. Yang, D. P. Thomas, X. Zhang et al., "Curcumin inhibits platelet-derived growth factor-stimulated vascular smooth muscle cell function and injury-induced neointima formation," Arteriosclerosis, Thrombosis, and Vascular Biology, vol. 26, no. 1, pp. 85-90, 2006.

[27] A. Goel, C. R. Boland, and D. P. Chauhan, "Specific inhibition of cyclooxygenase-2 (COX-2) expression by dietary curcumin in HT-29 human colon cancer cells," Cancer Letters, vol. 172, no. 2, pp. 111-118, 2001.

[28] J. Epstein, I. R. Sanderson, and T. T. MacDonald, "Curcumin as a therapeutic agent: the evidence from in vitro, animal and human studies," British Journal of Nutrition, vol. 103, no. 11, pp. 1545-1557, 2010.

[29] E. Skrzypczak-Jankun, N. P. McCabe, S. H. Selman, and J. Jankun, "Curcumin inhibits lipoxygenase by binding to its central cavity: theoretical and X-ray evidence." International Journal of Molecular Medicine, vol. 6, no. 5, pp. 521-526, 2000.

[30] R. Lin, X. Chen, W. Li, Y. Han, P. Liu, and R. Pi, "Exposure to metal ions regulates mRNA levels of APP and BACE1 in PC12 cells: blockage by curcumin," Neuroscience Letters, vol. 440, no. 3, pp. 344-347, 2008.

[31] T. Hamaguchi, K. Ono, and M. Yamada, "Curcumin and Alzheimer's disease," CNS Neuroscience \& Therapeutics, vol. 16, no. 5, pp. 285-297, 2010.

[32] X. Zhang, W.-K. Yin, X.-D. Shi, and Y. Li, "Curcumin activates Wnt/ $\beta$-catenin signaling pathway through inhibiting the activity of GSK-3 $\beta$ in APPswe transfected SY5Y cells," European Journal of Pharmaceutical Sciences, vol. 42, no. 5, pp. 540-546, 2011. 
[33] J.-W. Cho, K.-S. Lee, and C.-W. Kim, "Curcumin attenuates the expression of IL-1 $\beta$, IL- 6 , and TNF- $\alpha$ as well as cyclin $\mathrm{E}$ in TNF- $\alpha$-treated HaCaT cells; NF- $\kappa$ B and MAPKs as potential upstream targets," International Journal of Molecular Medicine, vol. 19, no. 3, pp. 469-474, 2007.

[34] C. Natarajan and J. J. Bright, "Curcumin inhibits experimental allergic encephalomyelitis by blocking IL-12 signaling through Janus kinase-STAT pathway in T lymphocytes," The Journal of Immunology, vol. 168, no. 12, pp. 6506-6513, 2002.

[35] J. Epstein, G. Docena, T. T. MacDonald, and I. R. Sanderson, "Curcumin suppresses p38 mitogen-activated protein kinase activation, reduces IL-1 $\beta$ and matrix metalloproteinase- 3 and enhances IL-10 in the mucosa of children and adults with inflammatory bowel disease," British Journal of Nutrition, vol. 103, no. 6, pp. 824-832, 2010.

[36] C. B. Larmonier, J. K. Uno, K.-M. Lee et al., "Limited effects of dietary curcumin on Th-1 driven colitis in IL-10 deficient mice suggest an IL-10-dependent mechanism of protection," American Journal of Physiology-Gastrointestinal and Liver Physiology, vol. 295, no. 5, pp. G1079-G1091, 2008.

[37] G. Garcea, D. J. L. Jones, R. Singh et al., "Detection of curcumin and its metabolites in hepatic tissue and portal blood of patients following oral administration," British Journal of Cancer, vol. 90, no. 5, pp. 1011-1015, 2004.

[38] O. N. Gordon and C. Schneider, "Vanillin and ferulic acid: Not the major degradation products of curcumin," Trends in Molecular Medicine, vol. 18, no. 7, pp. 361-363, 2012.

[39] C. Schneider, O. N. Gordon, R. L. Edwards, and P. B. Luis, "Degradation of curcumin: from mechanism to biological implications," Journal of Agricultural and Food Chemistry, vol. 63, no. 35, pp. 7606-7614, 2015.

[40] A. Scott, K. M. Khan, J. L. Cook, and V. Duronio, "What is "inflammation"? Are we ready to move beyond Celsus?" British Journal of Sports Medicine, vol. 38, no. 3, pp. 248-249, 2004.

[41] M. Weidenbusch and H.-J. Anders, "Tissue microenvironments define and get reinforced by macrophage phenotypes in homeostasis or during inflammation, repair and fibrosis," Journal of Innate Immunity, vol. 4, no. 5-6, pp. 463-477, 2012.

[42] C. Savoia and E. L. Schiffrin, "Inflammation in hypertension," Current Opinion in Nephrology and Hypertension, vol. 15, no. 2, pp. 152-158, 2006.

[43] C. J. Boos and G. Y. H. Lip, "Elevated high-sensitive Creactive protein, large arterial stiffness and atherosclerosis: A relationship between inflammation and hypertension?" Journal of Human Hypertension, vol. 19, no. 7, pp. 511-513, 2005.

[44] P. A. Zunszain, N. Hepgul, and C. M. Pariante, "Inflammation and depression," in Behavioral Neurobiology of Depression and Its Treatment, pp. 135-151, Springer, 2013.

[45] R. Dantzer, J. C. O’Connor, M. A. Lawson, and K. W. Kelley, "Inflammation-associated depression: from serotonin to kynurenine," Psychoneuroendocrinology, vol. 36, no. 3, pp. 426436, 2011.

[46] K. Löbner and M. Füchtenbusch, "Inflammation and diabetes," MMW - Fortschritte der Medizin, vol. 146, no. 35-36, pp. 32-36, 2004.

[47] P. Trayhurn and I. S. Wood, "Signalling role of adipose tissue: adipokines and inflammation in obesity," Biochemical Society Transactions, vol. 33, no. 5, pp. 1078-1081, 2005.

[48] M. C. Arkan, A. L. Hevener, F. R. Greten et al., "IKK- $\beta$ links inflammation to obesity-induced insulin resistance," Nature Medicine, vol. 11, no. 2, pp. 191-198, 2005.
[49] Y.-H. Lee and R. E. Pratley, “The evolving role of inflammation in obesity and the metabolic syndrome," Current Diabetes Reports, vol. 5, no. 1, pp. 70-75, 2005.

[50] H. Zhong, M. J. May, E. Jimi, and S. Ghosh, "The phosphorylation status of nuclear NF- $\kappa \mathrm{B}$ determines its association with CBP/p300 or HDAC-1," Molecular Cell, vol. 9, no. 3, pp. 625636, 2002.

[51] F. Emmerich, M. Meiser, M. Hummel et al., "Overexpression of I kappa B alpha without inhibition of NF- $\kappa$ B activity and mutations in the I kappa B alpha gene in Reed-Sternberg cells," Blood, vol. 94, no. 9, pp. 3129-3134, 1999.

[52] B. Beutler, K. Hoebe, X. Du, E. Janssen, P. Georgel, and K. Tabeta, "Lps2 and signal transduction in sepsis: at the intersection of host responses to bacteria and viruses," Scandinavian Journal of Infectious Diseases, vol. 35, no. 9, pp. 563-567, 2003.

[53] R. W. O’Rourke, “Molecular mechanisms of obesity and diabetes: At the intersection of weight regulation, inflammation, and glucose homeostasis," World Journal of Surgery, vol. 33, no. 10, pp. 2007-2013, 2009.

[54] J. Hiscott, H. Kwon, and P. Génin, "Hostile takeovers: Viral appropriation of the NF- $\kappa \mathrm{B}$ pathway," The Journal of Clinical Investigation, vol. 107, no. 2, pp. 143-151, 2001.

[55] P. A. Baeuerle and T. Henkel, "Function and activation of NF$\kappa \mathrm{B}$ in the immune system," Annual Review of Immunology, vol. 12, pp. 141-179, 1994.

[56] E. Tapia, V. Soto, K. M. Ortiz-Vega et al., "Curcumin induces Nrf2 nuclear translocation and prevents glomerular hypertension, hyperfiltration, oxidant stress, and the decrease in antioxidant enzymes in 5/6 nephrectomized rats," Oxidative Medicine and Cellular Longevity, vol. 2012, Article ID 269039, 14 pages, 2012.

[57] R. Bargou, C. Leng, D. Krappmann et al., "High-level nuclear NF-kappa B and Oct-2 is a common feature of cultured Hodgkin/Reed-Sternberg cells," Blood, vol. 87, no. 10, pp. 43404347, 1996.

[58] I. M. Verma, J. K. Stevenson, E. M. Schwarz, D. Van Antwerp, and S. Miyamoto, "Rel/NF-kappa B/I kappa B family: intimate tales of association and dissociation," Genes \& Development, vol. 9, no. 22, pp. 2723-2735, 1995.

[59] E. J. Duh, W. J. Maury, T. M. Folks, A. S. Fauci, and A. B. Rabson, "Tumor necrosis factor $\alpha$ activates human immunodeficiency virus type 1 through induction of nuclear factor binding to the NF- $\kappa \mathrm{B}$ sites in the long terminal repeat," Proceedings of the National Acadamy of Sciences of the United States of America, vol. 86, no. 15, pp. 5974-5978, 1989.

[60] H. L. Pahl, "Activators and target genes of Rel/NF-kappaB transcription factors," Oncogene, vol. 18, no. 49, pp. 6853-6866, 1999.

[61] D. G. Franco and R. P. Markus, “The cellular state determines the effect of melatonin on the survival of mixed cerebellar cell culture," PLoS ONE, vol. 9, no. 9, Article ID e106332, 2014.

[62] W. Xiao, "Advances in NF-kappaB signaling transduction and transcription," Cellular \& Molecular Immunology, vol. 1, no. 6, pp. 425-435, 2004.

[63] B. Kaltschmidt, D. Widera, and C. Kaltschmidt, "Signaling via NF- $\kappa \mathrm{B}$ in the nervous system," Biochimica et Biophysica Acta (BBA) - Molecular Cell Research, vol. 1745, no. 3, pp. 287-299, 2005.

[64] R. Schreck, P. Rieber, and P. A. Baeuerle, "Reactive oxygen intermediates as apparently widely used messengers in the activation of the NF- $\kappa$ B transcription factor and HIV-1," EMBO Journal, vol. 10, no. 8, pp. 2247-2258, 1991. 
[65] D.-Y. Lu, C.-H. Tang, W.-L. Yeh et al., "SDF-lalpha upregulates interleukin-6 through CXCR4, PI3K/Akt, ERK, and NF-kappaB-dependent pathway in microglia," European Journal of Pharmacology, vol. 613, no. 1-3, pp. 146-154, 2009.

[66] B. Stein and M. X. Yang, "Repression of the interleukin-6 promoter by estrogen receptor is mediated by NF- $\kappa \mathrm{B}$ and C/EBP $\beta$," Molecular \& Cellular Biology, vol. 15, no. 9, pp. 49714979, 1995.

[67] T. Matsusaka, K. Fujikawa, Y. Nishio et al., "Transcription factors NF-IL6 and NF- $\kappa$ B synergistically activate transcription of the inflammatory cytokines, interleukin 6 and interleukin 8," Proceedings of the National Acadamy of Sciences of the United States of America, vol. 90, no. 21, pp. 10193-10197, 1993.

[68] S. Appel, V. Mirakaj, A. Bringmann, M. M. Weck, F. Grünebach, and P. Brossart, "PPAR- $\gamma$ agonists inhibit toll-like receptormediated activation of dendritic cells via the MAP kinase and NF- $\kappa$ B pathways," Blood, vol. 106, no. 12, pp. 3888-3894, 2005.

[69] M. A. El Gazzar, R. El Mezayen, M. R. Nicolls, and S. C. Dreskin, "Thymoquinone attenuates proinflammatory responses in lipopolysaccharide-activated mast cells by modulating NFkappaB nuclear transactivation," Biochimica et Biophysica Acta (BBA) - General Subjects, vol. 1770, no. 4, pp. 556-564, 2007.

[70] T. A. Bird, K. Schooley, S. K. Dower, H. Hagen, and G. D. Virca, "Activation of nuclear transcription factor NF- $\kappa$ B by interleukin-1 is accompanied by casein kinase II-mediated phosphorylation of the p65 subunit," The Journal of Biological Chemistry, vol. 272, no. 51, pp. 32606-32612, 1997.

[71] M. J. Suto and A. M. Manning, "Inhibition of NF-кB," in High Throughput Screening for Novel Anti-Inflammatories, pp. 193204, Springer, 2000.

[72] M. Karin, "How NF- $\kappa \mathrm{B}$ is activated: the role of the $\mathrm{I} \kappa \mathrm{B}$ kinase (IKK) complex," Oncogene, vol. 18, no. 49, pp. 6867-6874, 1999.

[73] L. Ling, Z. Cao, and D. V. Goeddel, "Nf- $\kappa B$-inducing kinase activates IKK- $\alpha$ by phosphorylation of Ser-176," Proceedings of the National Acadamy of Sciences of the United States of America, vol. 95, no. 7, pp. 3792-3797, 1998.

[74] D.-F. Lee and M.-C. Hung, "Advances in targeting IKK and IKKrelated kinases for cancer therapy," Clinical Cancer Research, vol. 14, no. 18, pp. 5656-5662, 2008.

[75] M. Karin, Y. Yamamoto, and Q. M. Wang, "The IKK NF- $\kappa$ B system: a treasure trove for drug development," Nature Reviews Drug Discovery, vol. 3, no. 1, pp. 17-26, 2004.

[76] K. Clark, M. Peggie, L. Plater et al., "Novel cross-talk within the IKK family controls innate immunity," Biochemical Journal, vol. 434, no. 1, pp. 93-104, 2011.

[77] A. Hoffmann, A. Levchenko, M. L. Scott, and D. Baltimore, "The $\mathrm{I} \kappa \mathrm{B}-\mathrm{NF}-\kappa \mathrm{B}$ signaling module: temporal control and selective gene activation," Science, vol. 298, no. 5596, pp. 1241-1245, 2002.

[78] R. Eric Davis, K. D. Brown, U. Siebenlist, and L. M. Staudt, "Constitutive nuclear factor $\kappa \mathrm{B}$ activity is required for survival of activated B cell-like diffuse large B cell lymphoma cells," The Journal of Experimental Medicine, vol. 194, no. 12, pp. 1861-1874, 2001.

[79] P. F. Gomez, M. H. Pillinger, M. Attur et al., "Resolution of inflammation: Prostaglandin E2 dissociates nuclear trafficking of individual NF- $\kappa$ B subunits (p65, p50) in stimulated rheumatoid synovial fibroblasts," The Journal of Immunology, vol. 175, no. 10, pp. 6924-6930, 2005.

[80] Y.-Q. Chen, S. Ghosh, and G. Ghosh, "A novel DNA recognition mode by the NF- $\kappa$ b p 65 homodimer," Nature Structural \& Molecular Biology, vol. 5, no. 1, pp. 67-73, 1998.
[81] T. Fujita, G. P. Nolan, S. Ghosh, and D. Baltimore, "Independent modes of transcriptional activation by the $\mathrm{p} 50$ and $\mathrm{p} 65$ subunits of NF-kappa B," Genes \& Development, vol. 6, no. 5, pp. 775-787, 1992.

[82] C. Kunsch, S. M. Ruben, and C. A. Rosen, "Selection of optimal $\kappa \mathrm{B} /$ Rel DNA-binding motifs: Interaction of both subunits of $\mathrm{NF}-\kappa \mathrm{B}$ with DNA is required for transcriptional activation," Molecular and Cellular Biology, vol. 12, no. 10, pp. 4412-4421, 1992.

[83] C. Y. Sasaki, T. J. Barberi, P. Ghosh, and D. L. Longo, "Phosphorylation of RelA/p65 on serine 536 defines an $\mathrm{I} \kappa \mathrm{B} \alpha$ independent NF- $\kappa \mathrm{B}$ pathway," The Journal of Biological Chemistry, vol. 280, no. 41, pp. 34538-34547, 2005.

[84] J. Anrather, G. Racchumi, and C. Iadecola, "cis-Acting elementspecific transcriptional activity of differentially phosphorylated nuclear factor- $\kappa \mathrm{B}$," The Journal of Biological Chemistry, vol. 280, no. 1, pp. 244-252, 2005.

[85] M. L. Schmitz, I. Mattioli, H. Buss, and M. Kracht, "NF- $\kappa B$ : A multifaceted transcription factor regulated at several levels," ChemBioChem, vol. 5, no. 10, pp. 1348-1358, 2004.

[86] H. Sakurai, H. Chiba, H. Miyoshi, T. Sugita, and W. Toriumi, "I $\kappa \mathrm{B}$ kinases phosphorylate NF- $\kappa \mathrm{B}$ p65 subunit on serine 536 in the transactivation domain," The Journal of Biological Chemistry, vol. 274, no. 43, pp. 30353-30356, 1999.

[87] D. Wang and A. S. Baldwin Jr., "Activation of nuclear factor- $\kappa$ Bdependent transcription by tumor necrosis factor- $\alpha$ is mediated through phosphorylation of RelA/p65 on serine 529," The Journal of Biological Chemistry, vol. 273, no. 45, pp. 29411-29416, 1998.

[88] N. Sizemore, S. Leung, and G. R. Stark, "Activation of phosphatidylinositol 3-kinase in response to interleukin- 1 leads to phosphorylation and activation of the NF- $\kappa$ B p65/RelA subunit," Molecular and Cellular Biology, vol. 19, no. 7, pp. 47984805, 1999.

[89] S. Ryan, W. T. McNicholas, and C. T. Taylor, "A critical role for p38 map kinase in NF- $\kappa \mathrm{B}$ signaling during intermittent hypoxia/reoxygenation," Biochemical and Biophysical Research Communications, vol. 355, no. 3, pp. 728-733, 2007.

[90] S. T. Smale, "Hierarchies of NF- $\kappa$ B target-gene regulation," Nature Immunology, vol. 12, no. 8, pp. 689-694, 2011.

[91] Y.-H. Son, Y.-T. Jeong, K.-A. Lee et al., "Roles of MAPK and NF$\kappa \mathrm{B}$ in interleukin- 6 induction by lipopolysaccharide in vascular smooth muscle cells," Journal of Cardiovascular Pharmacology, vol. 51, no. 1, pp. 71-77, 2008.

[92] P. Delerive, P. Gervois, J.-C. Fruchart, and B. Staels, "Induction of $\mathrm{I} \kappa \mathrm{B} \alpha$ expression as a mechanism contributing to the antiinflammatory activities of peroxisome proliferator-activated receptor- $\alpha$ activators," The Journal of Biological Chemistry, vol. 275, no. 47, pp. 36703-36707, 2000.

[93] X. Jiang, N. Takahashi, K. Ando, T. Otsuka, T. Tetsuka, and T. Okamoto, "NF- $\kappa$ B p 65 transactivation domain is involved in the $\mathrm{NF}-\kappa \mathrm{B}$-inducing kinase pathway," Biochemical and Biophysical Research Communications, vol. 301, no. 2, pp. 583-590, 2003.

[94] N. D. Perkins, N. L. Edwards, C. S. Duckett, A. B. Agranoff, R. M. Schmid, and G. J. Nabel, "A cooperative interaction between NF-kappa B and Spl is required for HIV-1 enhancer activation," EMBO Journal, vol. 12, no. 9, pp. 3551-3558, 1993.

[95] A. D. Yurochko, T. F. Kowalik, S. M. Huong, and E. S. Huang, "Human cytomegalovirus upregulates NF-kappa B activity by transactivating the NF-kappa B p105/p50 and p65 promoters," Journal of Virology, vol. 69, no. 9, pp. 5391-5400, 1995. 
[96] L. I. McKay and J. A. Cidlowski, "CBP (CREB binding protein) integrates NF- $\kappa \mathrm{B}$ (nuclear factor- $\kappa \mathrm{B}$ ) and glucocorticoid receptor physical interactions and antagonism," Molecular Endocrinology, vol. 14, no. 8, pp. 1222-1234, 2000.

[97] D. B. Starr and D. K. Hawley, "TFIID binds in the minor groove of the TATA box," Cell, vol. 67, no. 6, pp. 1231-1240, 1991.

[98] R. Drapkin, A. Merino, and D. Reinberg, "Regulation of RNA polymerase II transcription," Current Opinion in Cell Biology, vol. 5, no. 3, pp. 469-476, 1993.

[99] Y. Yumi, U. N. Verma, S. Prajapati, K. Youn-Tae, and R. B. Gaynor, "Histone H3 phosphorylation by ikk- $\alpha$ is critical for cytokine-induced gene expression," Nature, vol. 423, no. 6940, pp. 655-659, 2003.

[100] G. D. Bren, N. J. Solan, H. Miyoshi, K. N. Pennington, L. J. Pobst, and C. V. Paya, "Transcription of the RelB gene is regulated by NF- $\kappa$ B," Oncogene, vol. 20, no. 53, pp. 7722-7733, 2001.

[101] Y. Lavrovsky, B. Chatterjee, R. A. Clark, and A. K. Roy, "Role of redox-regulated transcription factors in inflammation, aging and age-related diseases," Experimental Gerontology, vol. 35, no. 5, pp. 521-532, 2000.

[102] N. D. Perkins, "Integrating cell-signalling pathways with NF- $\kappa \mathrm{B}$ and IKK function," Nature Reviews Molecular Cell Biology, vol. 8, no. 1, pp. 49-62, 2007.

[103] M. Woo, S. Jung, S. Kim et al., "Curcumin suppresses phorbol ester-induced matrix metalloproteinase- 9 expression by inhibiting the PKC to MAPK signaling pathways in human astroglioma cells," Biochemical and Biophysical Research Communications, vol. 335, no. 4, pp. 1017-1025, 2005.

[104] S. Singh and B. B. Aggarwal, "Activation of transcription factor NF- $\kappa \mathrm{B}$ is suppressed by curcumin (diferuloylmethane)," The Journal of Biological Chemistry, vol. 270, no. 42, pp. 2499525000, 1995.

[105] L. Vermeulen, G. De Wilde, P. Van Damme, W. V. Berghe, and G. Haegeman, "Transcriptional activation of the NF- $\kappa$ B p65 subunit by mitogen- and stress-activated protein kinase-1 (MSK1)," EMBO Journal, vol. 22, no. 6, pp. 1313-1324, 2003.

[106] G. Pearson, F. Robinson, T. B. Gibson et al., "Mitogen-activated protein (MAP) kinase pathways: regulation and physiological functions," Endocrine Reviews, vol. 22, no. 2, pp. 153-183, 2001.

[107] G.-Y. Kim, K.-H. Kim, S.-H. Lee et al., "Curcumin inhibits immunostimulatory function of dendritic cells: MAPKs and translocation of NF- $\kappa \mathrm{B}$ as potential targets," The Journal of Immunology, vol. 174, no. 12, pp. 8116-8124, 2005.

[108] D. G. Binion, M. F. Otterson, and P. Rafiee, "Curcumin inhibits VEGF-mediated angiogenesis in human intestinal microvascular endothelial cells through COX-2 and MAPK inhibition," Gut, vol. 57, no. 11, pp. 1509-1517, 2008.

[109] D. G. Adams, R. L. Coffee Jr., H. Zhang, S. Pelech, S. Strack, and B. E. Wadzinski, "Positive regulation of Rafl-MEK1/2ERK1/2 signaling by protein serine/threonine phosphatase $2 \mathrm{~A}$ holoenzymes," The Journal of Biological Chemistry, vol. 280, no. 52, pp. 42644-42654, 2005.

[110] G. L. Johnson and R. Lapadat, "Mitogen-activated protein kinase pathways mediated by ERK, JNK, and p38 protein kinases," Science, vol. 298, no. 5600, pp. 1911-1912, 2002.

[111] A. Carracedo, L. Ma, and J. Teruya-Feldstein, "Inhibition of mTORC1 leads to MAPK pathway activation through a PI3Kdependent feedback loop in human cancer," The Journal of Clinical Investigation, vol. 118, no. 9, pp. 3065-3074, 2008.

[112] W. E. Tidyman and K. A. Rauen, "The RASopathies: developmental syndromes of Ras/MAPK pathway dysregulation,"
Current Opinion in Genetics \& Development, vol. 19, no. 3, pp. 230-236, 2009.

[113] K. F. Chung, "p38 mitogen-activated protein kinase pathways in asthma and COPD," CHEST, vol. 139, no. 6, pp. 1470-1479, 2011.

[114] S. Matthiesen, A. Bahulayan, O. Holz, and K. Racké, "MAPK pathway mediates muscarinic receptor-induced human lung fibroblast proliferation," Life Sciences, vol. 80, no. 24-25, pp. 2259-2262, 2007.

[115] M. R. Junttila, S.-P. Li, and J. Westermarck, "Phosphatasemediated crosstalk between MAPK signaling pathways in the regulation of cell survival," The FASEB Journal, vol. 22, no. 4, pp. 954-965, 2008.

[116] A. Bonni, A. Brunet, A. E. West, S. R. Datta, M. A. Takasu, and M. E. Greenberg, "Cell survival promoted by the RasMAPK signaling pathway by transcription-dependent and independent mechanisms," Science, vol. 286, no. 5443, pp. 13581362, 1999.

[117] T. Okazaki, S. Sakon, T. Sasazuki et al., "Phosphorylation of serine 276 is essential for p $65 \mathrm{NF}-\kappa \mathrm{B}$ subunit-dependent cellular responses," Biochemical and Biophysical Research Communications, vol. 300, no. 4, pp. 807-812, 2003.

[118] A. S. Baldwin Jr., "The NF- $\kappa$ B and $\mathrm{I} \kappa \mathrm{B}$ proteins: new discoveries and insights," Annual Review of Immunology, vol. 14, pp. 649683, 1996.

[119] P. Viatour, M. Merville, V. Bours, and A. Chariot, "Phosphorylation of NF- $\kappa \mathrm{B}$ and $\mathrm{I} \kappa \mathrm{B}$ proteins: implications in cancer and inflammation," Trends in Biochemical Sciences, vol. 30, no. 1, pp. 43-52, 2005.

[120] F. Chang, L. S. Steelman, J. T. Lee et al., "Signal transduction mediated by the Ras/Raf/MEK/ERK pathway from cytokine receptors to transcription factors: Potential targeting for therapeutic intervention," Leukemia, vol. 17, no. 7, pp. 1263-1293, 2003.

[121] A. Oeckinghaus, M. S. Hayden, and S. Ghosh, "Crosstalk in NF$\kappa \mathrm{B}$ signaling pathways," Nature Immunology, vol. 12, no. 8, pp. 695-708, 2011.

[122] H. F. Kramer and L. J. Goodyear, "Exercise, MAPK, and NF- $\kappa$ B signaling in skeletal muscle," Journal of Applied Physiology, vol. 103, no. 1, pp. 388-395, 2007.

[123] W. Min, Z. W. Bin, Z. B. Quan, Z. J. Hui, and F. G. Sheng, "The signal transduction pathway of $\mathrm{PKC} / \mathrm{NF}-\kappa \mathrm{B} / \mathrm{c}$-fos may be involved in the influence of high glucose on the cardiomyocytes of neonatal rats," Cardiovascular Diabetology, vol. 8, article 8, 2009.

[124] M. L. Schmitz, M. A. Dos Santos Silva, and P. A. Baeuerle, "Transactivation domain 2 (TA2) of p65 NF- $\kappa$ B. Similarity to TA1 and phorbol ester-stimulated activity and phosphorylation in intact cells," The Journal of Biological Chemistry, vol. 270, no. 26, pp. 15576-15584, 1995.

[125] H. Zhong, R. E. Voll, and S. Ghosh, "Phosphorylation of NF$\kappa \mathrm{B}$ p65 by PKA stimulates transcriptional activity by promoting a novel bivalent interaction with the coactivator CBP/p300," Molecular Cell, vol. 1, no. 5, pp. 661-671, 1998.

[126] J. Xing, D. D. Ginty, and M. E. Greenberg, "Coupling of the RAS-MAPK pathway to gene activation by RSK2, a growth factor-regulated CREB kinase," Science, vol. 273, no. 5277, pp. 959-963, 1996.

[127] M. Deak, A. D. Clifton, J. M. Lucocq, and D. R. Alessi, "Mitogenand stress-activated protein kinase-1 (MSK1) is directly activated by MAPK and SAPK2/p38, and may mediate activation of CREB," EMBO Journal, vol. 17, no. 15, pp. 4426-4441, 1998. 
[128] D. Chauhan, H. Uchiyama, Y. Akbarali et al., "Multiple myeloma cell adhesion-induced interleukin- 6 expression in bone marrow stromal cells involves activation of NF-kappa B," Blood, vol. 3, pp. 1104-1112, 87.

[129] M. Karin and A. Lin, "NF- $\kappa$ B at the crossroads of life and death," Nature Immunology, vol. 3, no. 3, pp. 221-227, 2002.

[130] J. J. Wu and A. M. Bennett, "Essential role for mitogen-activated protein (MAP) kinase phosphatase-1 in stress-responsive MAP kinase and cell survival signaling," The Journal of Biological Chemistry, vol. 280, no. 16, pp. 16461-16466, 2005.

[131] J.-M. Yun, I. Jialal, and S. Devaraj, "Epigenetic regulation of high glucose-induced proinflammatory cytokine production in monocytes by curcumin," The Journal of Nutritional Biochemistry, vol. 22, no. 5, pp. 450-458, 2011.

[132] J. Gao, H. Zhou, T. Lei et al., "Curcumin inhibits renal cyst formation and enlargement in vitro by regulating intracellular signaling pathways," European Journal of Pharmacology, vol. 654, no. 1, pp. 92-99, 2011.

[133] Y. Guo, Q. Shan, Y. Gong et al., "Curcumin induces apoptosis via simultaneously targeting AKT/mTOR and RAF/MEK/ERK survival signaling pathways in human leukemia THP-1 cells," Die Pharmazie-An International Journal of Pharmaceutical Sciences, vol. 69, no. 3, pp. 229-233, 2014.

[134] I. Jutooru, G. Chadalapaka, P. Lei, and S. Safe, "Inhibition of $\mathrm{NF} \kappa \mathrm{B}$ and pancreatic cancer cell and tumor growth by curcumin is dependent on specificity protein down-regulation," The Journal of Biological Chemistry, vol. 285, no. 33, pp. 2533225344, 2010.

[135] F. D'Acquisto, M. J. May, and S. Ghosh, "Inhibition of nuclear factor kappa B (NF-B): an emerging theme in antiinflammatory therapies.," Molecular Interventions, vol. 2, no. 1, pp. 22-35, 2002.

[136] I. Brouet and H. Ohshima, "Curcumin, an anti-tumour promoter and anti-inflammatory agent, inhibits induction of nitric oxide synthase in activated macrophages," Biochemical and Biophysical Research Communications, vol. 206, no. 2, pp. 533540, 1995.

[137] A. C. Bharti, N. Donato, S. Singh, and B. B. Aggarwal, "Curcumin (diferuloylmethane) down-regulates the constitutive activation of nuclear factor- $\kappa \mathrm{B}$ and $\mathrm{I} \kappa \mathrm{B} \alpha$ kinase in human multiple myeloma cells, leading to suppression of proliferation and induction of apoptosis," Blood, vol. 101, no. 3, pp. 1053-1062, 2003.

[138] S. Shishodia, H. M. Amin, R. Lai, and B. B. Aggarwal, "Curcumin (diferuloylmethane) inhibits constitutive NF- $\kappa$ B activation, induces G1/S arrest, suppresses proliferation, and induces apoptosis in mantle cell lymphoma," Biochemical Pharmacology, vol. 70, no. 5, pp. 700-713, 2005.

[139] A. L. Berger, C. O. Randak, L. S. Ostedgaard, P. H. Karp, D. W. Vermeer, and M. J. Welsh, "Curcumin stimulates cystic fibrosis transmembrane conductance regulator $\mathrm{Cl}$ - channel activity," The Journal of Biological Chemistry, vol. 280, no. 7, pp. 52215226, 2005.

[140] F. Zhang, N. K. Altorki, J. R. Mestre, K. Subbaramaiah, and A. J. Dannenberg, "Curcumin inhibits cyclooxygenase-2 transcription in bile acid- and phorbol ester-treated human gastrointestinal epithelial cells," Carcinogenesis, vol. 20, no. 3, pp. 445-451, 1999.

[141] J. Holy, "Curcumin inhibits cell motility and alters microfilament organization and function in prostate cancer cells," Cell Motility and the Cytoskeleton, vol. 58, no. 4, pp. 253-268, 2004.
[142] J.-Y. Liu, S.-J. Lin, and J.-K. Lin, "Inhibitory effects of curcumin on protein kinase $\mathrm{C}$ activity induced by 12 -O-tetradecanoylphorbol-13-acetate in MH 3T3 cells," Carcinogenesis, vol. 14, no. 5, pp. 857-861, 1993.

[143] Y. Tanaka, M. V. Gavrielides, Y. Mitsuuchi, T. Fujii, and M. G. Kazanietz, "Protein Kinase C Promotes Apoptosis in LNCaP Prostate Cancer Cells through Activation of p38 MAPK and Inhibition of the Akt Survival Pathway," The Journal of Biological Chemistry, vol. 278, no. 36, pp. 33753-33762, 2003.

[144] G.-Y. Wu, K. Deisseroth, and R. W. Tsien, "Spaced stimuli stabilize MAPK pathway activation and its effects on dendritic morphology," Nature Neuroscience, vol. 4, no. 2, pp. 151-158, 2001.

[145] S. Reddy and B. B. Aggarwal, "Curcumin is a non-competitive and selective inhibitor of phosphorylase kinase," FEBS Letters, vol. 341, no. 1, pp. 19-22, 1994.

[146] M. Wang, Y. Ruan, Q. Chen, S. Li, Q. Wang, and J. Cai, "Curcumin induced HepG2 cell apoptosis-associated mitochondrial membrane potential and intracellular free $\mathrm{Ca} 2+$ concentration," European Journal of Pharmacology, vol. 650, no. 1, pp. 41-47, 2011.

[147] J. A. Bush, K.-J. J. Cheung, and G. Li, "Curcumin induces apoptosis in human melanoma cells through a Fas receptor/caspase8 pathway independent of p53," Experimental Cell Research, vol. 271, no. 2, pp. 305-314, 2001.

[148] T. Choudhuri, S. Pal, T. Das, and G. Sa, "Curcumin selectively induces apoptosis in deregulated cyclin D1-expressed cells at G2 phase of cell cycle in a p53-dependent manner," The Journal of Biological Chemistry, vol. 280, no. 20, pp. 20059-20068, 2005.

[149] R. J. Anto, A. Mukhopadhyay, K. Denning, and B. B. Aggarwal, "Curcumin (diferuloylmethane) induces apoptosis through activation of caspase- 8 , BID cleavage and cytochrome $c$ release: its suppression by ectopic expression of Bcl-2 and Bcl-xl," Carcinogenesis, vol. 23, no. 1, pp. 143-150, 2002.

[150] R. Wilken, M. S. Veena, M. B. Wang, and E. S. Srivatsan, "Curcumin: a review of anti-cancer properties and therapeutic activity in head and neck squamous cell carcinoma," Molecular Cancer, vol. 10, article 12, 2011.

[151] S. Swarnakar, K. Ganguly, P. Kundu, A. Banerjee, P. Maity, and A. V. Sharma, "Curcumin regulates expression and activity of matrix metalloproteinases 9 and 2 during prevention and healing of indomethacin-induced gastric ulcer," The Journal of Biological Chemistry, vol. 280, no. 10, pp. 9409-9415, 2005.

[152] C. M. Kaefer and J. A. Milner, "The role of herbs and spices in cancer prevention," The Journal of Nutritional Biochemistry, vol. 19, no. 6, pp. 347-361, 2008.

[153] Q. Li and I. M. Verma, "NF- $\kappa$ B regulation in the immune system," Nature Reviews Immunology, vol. 2, no. 10, pp. 725-734, 2002.

[154] K.-S. Chun, Y.-S. Keum, S. S. Han, Y.-S. Song, S.-H. Kim, and Y.J. Surh, "Curcumin inhibits phorbol ester-induced expression of cyclooxygenase-2 in mouse skin through suppression of extracellular signal-regulated kinase activity and NF- $\kappa$ B activation," Carcinogenesis, vol. 24, no. 9, pp. 1515-1524, 2003.

[155] C. Jobin, C. A. Bradham, M. P. Russo et al., "Curcumin blocks cytokine-mediated NF- $\kappa$ B activation and proinflammatory gene expression by inhibiting inhibitory factor $\mathrm{I}-\kappa \mathrm{B}$ kinase activity," The Journal of Immunology, vol. 163, no. 6, pp. 34743483, 1999.

[156] L. Martelli, E. Ragazzi, F. Di Mario et al., "A potential role for the vanilloid receptor TRPV1 in the therapeutic effect of 
curcumin in dinitrobenzene sulphonic acid-induced colitis in mice," Neurogastroenterology \& Motility, vol. 19, no. 8, pp. 668674, 2007.

[157] K. Meghana, G. Sanjeev, and B. Ramesh, "Curcumin prevents streptozotocin-induced islet damage by scavenging free radicals: a prophylactic and protective role," European Journal of Pharmacology, vol. 577, no. 1-3, pp. 183-191, 2007.

[158] H.-Y. Hsu, L.-C. Chu, K.-F. Hua, and L. K. Chao, "Heme oxygenase-1 mediates the anti-inflammatory effect of curcumin within LPS-stimulated human monocytes," Journal of Cellular Physiology, vol. 215, no. 3, pp. 603-612, 2008.

[159] M. A. El-Moselhy, A. Taye, S. S. Sharkawi, S. F. I. El-Sisi, and A. F. Ahmed, "The antihyperglycemic effect of curcumin in high fat diet fed rats. Role of TNF- $\alpha$ and free fatty acids," Food and Chemical Toxicology, vol. 49, no. 5, pp. 1129-1140, 2011.

[160] P. Suresh Babu and K. Srinivasan, "Influence of dietary curcumin and cholesterol on the progression of experimentally induced diabetes in albino rat," Molecular and Cellular Biochemistry, vol. 152, no. 1, pp. 13-21, 1995.

[161] L. L. Hurley, L. Akinfiresoye, E. Nwulia, A. Kamiya, A. A. Kulkarni, and Y. Tizabi, "Antidepressant-like effects of curcumin in WKY rat model of depression is associated with an increase in hippocampal BDNF," Behavioural Brain Research, vol. 239, no. 1, pp. 27-30, 2013.

[162] J. Sanmukhani, A. Anovadiya, and C. B. Tripathi, "Evaluation of antidepressant like activity of curcumin and its combination with fluoxetine and imipramine: An acute and chronic study," Acta Poloniae Pharmaceutica. Drug Research, vol. 68, no. 5, pp. 769-775, 2011.

[163] W. Wongcharoen and A. Phrommintikul, "The protective role of curcumin in cardiovascular diseases," International Journal of Cardiology, vol. 133, no. 2, pp. 145-151, 2009.

[164] T. Morimoto, Y. Sunagawa, T. Kawamura et al., "The dietary compound curcumin inhibits p300 histone acetyltransferase activity and prevents heart failure in rats," The Journal of Clinical Investigation, vol. 118, no. 3, pp. 868-878, 2008.

[165] M. Gharate, "Rheumatoid arthritis \& Complementary and Alternative Medicine," Pharmainfo. net, 5, 2007.

[166] M. E. Egan, M. Pearson, S. A. Weiner et al., "Curcumin, a Major Constituent of Turmeric, Corrects Cystic Fibrosis Defects," Science, vol. 304, no. 5670, pp. 600-602, 2004.

[167] G. Allam, "Immunomodulatory effects of curcumin treatment on murine schistosomiasis mansoni," Immunobiology, vol. 214, no. 8, pp. 712-727, 2009.

[168] S. Mishra and K. Palanivelu, "The effect of curcumin (turmeric) on Alzheimer's disease: an overview," Annals of Indian Academy of Neurology, vol. 11, no. 1, pp. 13-19, 2008.

[169] S. J. Moghaddam, P. Barta, S. G. Mirabolfathinejad et al., "Curcumin inhibits COPD-like airway inflammation and lung cancer progression in mice," Carcinogenesis, vol. 30, no. 11, pp. 1949-1956, 2009.

[170] B. B. Aggarwal, "Targeting lammation-induced obesity and metabolic diseases by curcumin and other nutraceuticals," Annual Review of Nutrition, vol. 30, pp. 173-199, 2010.

[171] L. Alappat and A. B. Awad, "Curcumin and obesity: evidence and mechanisms," Nutrition Reviews, vol. 68, no. 12, pp. 729738, 2010.

[172] A. Shehzad, T. Ha, F. Subhan, and Y. S. Lee, "New mechanisms and the anti-inflammatory role of curcumin in obesity and obesity-related metabolic diseases," European Journal of Nutrition, vol. 50, no. 3, pp. 151-161, 2011.
[173] A. Belkacemi, S. Doggui, L. Dao, and C. Ramassamy, "Challenges associated with curcumin therapy in Alzheimer disease," Expert Reviews in Molecular Medicine, vol. 13, no. 5, p. e34, 2011.

[174] H.-J. Seo, S.-M. Wang, C. Han et al., "Curcumin as a putative antidepressant," Expert Review of Neurotherapeutics, vol. 15, no. 3, pp. 269-280, 2015.

[175] M. Mall and K. Kunzelmann, "Correction of the CF defect by curcumin: Hypes and disappointments," BioEssays, vol. 27, no. 1, pp. 9-13, 2005.

[176] C.-H. Hsu and A.-L. Cheng, "Clinical studies with curcumin," in The Molecular Targets and Therapeutic Uses of Curcumin in Health and Disease, pp. 471-480, Springer, 2007.

[177] A. Goel and B. B. Aggarwal, "Curcumin, the golden spice from Indian saffron, is a chemosensitizer and radiosensitizer for tumors and chemoprotector and radioprotector for normal organs," Nutrition and Cancer, vol. 62, no. 7, pp. 919-930, 2010.

[178] S. Ganta and M. Amiji, "Coadministration of paclitaxel and curcumin in nanoemulsion formulations to overcome multidrug resistance in tumor cells," Molecular Pharmaceutics, vol. 6, no. 3, pp. 928-939, 2009.

[179] S.-E. Chuang, P.-Y. Yeh, Y.-S. Lu et al., "Basal levels and patterns of anticancer drug-induced activation of nuclear factor- $\kappa \mathrm{B}$ (NF$\kappa \mathrm{B})$, and its attenuation by tamoxifen, dexamethasone, and curcumin in carcinoma cells," Biochemical Pharmacology, vol. 63, no. 9, pp. 1709-1716, 2002.

[180] J. Zhang, T. Zhang, X. Ti et al., "Curcumin promotes apoptosis in A549/DDP multidrug-resistant human lung adenocarcinoma cells through an miRNA signaling pathway," Biochemical and Biophysical Research Communications, vol. 399, no. 1, pp. 16, 2010.

[181] P. Venkatesan and M. N. A. Rao, "Structure-activity relationships for the inhibition of lipid peroxidation and the scavenging of free radicals by synthetic symmetrical curcumin analogues," Journal of Pharmacy and Pharmacology, vol. 52, no. 9, pp. 1123$1128,2000$.

[182] P. Anand, S. G. Thomas, A. B. Kunnumakkara et al., "Biological activities of curcumin and its analogues (Congeners) made by man and Mother Nature," Biochemical Pharmacology, vol. 76, no. 11, pp. 1590-1611, 2008.

[183] B.-K. Jadhav, K.-R. Mahadik, and A.-R. Paradkar, "Development and validation of improved reversed phase-HPLC method for simultaneous determination of curcumin, demethoxycurcumin and bis-demethoxycurcumin," Chromatographia, vol. 65, no. 7-8, pp. 483-488, 2007.

[184] J. Krasovsky, D. H. Chang, G. Deng et al., "Inhibition of human dendritic cell activation by hydroethanolic but not lipophilic extracts of turmeric (Curcuma longa)," Planta Medica, vol. 75, no. 4, pp. 312-315, 2009.

[185] V. P. Rodríguez, C. Sweet, B. N. Timmermann, and A. M. Sólyom, "Development of an LC/MS/MS method to separate and analyze curcuminoids, their metabolites and degradation products," 2004.

[186] M. Marsin Sanagi, U. K. Ahmad, and R. M. Smith, "Application of supercritical fluid extraction and chromatography to the analysis of turmeric," Journal of Chromatographic Science (JCS), vol. 31, no. 1, pp. 20-25, 1993.

[187] S. Anuchapreeda, W. Sadjapong, C. Duangrat, and P. Limtrakul, "The cytotoxic effect of curumin, demethoxycurcumin and bisdemethoxycurcumin purified from Turmeric powder on leukemic cell lines," Bulletin of Chiang Mai Associated Medical Sciences, vol. 39, no. 1, p. 60, 2006. 
[188] M.-T. Huang, W. Ma, Y.-P. Lu et al., "Effects of curcumin, demethoxycurcumin, bisdemethoxycurcumin and tetrahydrocurcumin on 12- $M$-tetradecanoylphorbol-13-acetate-induced tumor promotion," Carcinogenesis, vol. 16, no. 10, pp. 2493-2497, 1995.

[189] M. Balasubramanyam, A. A. Koteswari, R. S. Kumar, S. F. Monickaraj, J. U. Maheswari, and V. Mohan, "Curcumin-induced inhibition of cellular reactive oxygen species generation: novel therapeutic implications," Journal of Biosciences, vol. 28, no. 6, pp. 715-721, 2003.

[190] V. Soetikno, K. Watanabe, F. R. Sari et al., "Curcumin attenuates diabetic nephropathy by inhibiting PKC- $\alpha$ and PKC- $\beta 1$ activity in streptozotocin-induced type I diabetic rats," Molecular Nutrition \& Food Research, vol. 55, no. 11, pp. 1655-1665, 2011.

[191] S. A. Rushworth, R. M. Ogborne, C. A. Charalambos, and M. A. O'Connell, "Role of protein kinase $\mathrm{C} \delta$ in curcumin-induced antioxidant response element-mediated gene expression in human monocytes," Biochemical and Biophysical Research Communications, vol. 341, no. 4, pp. 1007-1016, 2006.

[192] Y. A. Mahmmoud, "Modulation of protein kinase C by curcumin; inhibition and activation switched by calcium ions," British Journal of Pharmacology, vol. 150, no. 2, pp. 200-208, 2007.

[193] R. A. Sharma, S. A. Euden, S. L. Platton et al., "Phase I clinical trial of oral curcumin: biomarkers of systemic activity and compliance," Clinical Cancer Research, vol. 10, no. 20, pp. 68476854, 2004.

[194] Y.-J. Wang, M.-H. Pan, A.-L. Cheng et al., "Stability of curcumin in buffer solutions and characterization of its degradation products," Journal of Pharmaceutical and Biomedical Analysis, vol. 15, no. 12, pp. 1867-1876, 1997.

[195] M.-T. Huang, R. C. Smart, C.-Q. Wong, and A. H. Conney, "Inhibitory effect of curcumin, chlorogenic acid, caffeic acid, and ferulic acid on tumor promotion in mouse skin by 12-Otetradecanoylphorbol-13-acetate," Cancer Research, vol. 48, no. 21, pp. 5941-5946, 1988.

[196] H. Kikuzaki, M. Hisamoto, K. Hirose, K. Akiyama, and H. Taniguchi, "Antioxidant properties of ferulic acid and its related compounds," Journal of Agricultural and Food Chemistry, vol. 50, no. 7, pp. 2161-2168, 2002.

[197] J. Kanski, M. Aksenova, A. Stoyanova, and D. A. Butterfield, "Ferulic acid antioxidant protection against hydroxyl and peroxyl radical oxidation in synaptosomal and neuronal cell culture systems in vitro: structure-activity studies," The Journal of Nutritional Biochemistry, vol. 13, no. 5, pp. 273-281, 2002.

[198] H. H. Tønnesen and J. Karlsen, "Studies on curcumin and curcuminoids - VI. Kinetics of curcumin degradation in aqueous solution," Zeitschrift für Lebensmittel-Untersuchung und Forschung, vol. 180, no. 5, pp. 402-404, 1985.

[199] L. Shen and H.-F. Ji, "Contribution of degradation products to the anticancer activity of curcumin," Clinical Cancer Research, vol. 15, no. 22, p. 7108, 2009.

[200] Y. Abe, S. Hashimoto, and T. Horie, "Curcumin inhibition of inflammatory cytokine production by human peripheral blood monocytes and alveolar macrophages," Pharmacological Research, vol. 39, no. 1, pp. 41-47, 1999.

[201] A. Paradkar, A. A. Ambike, B. K. Jadhav, and K. R. Mahadik, "Characterization of curcumin-PVP solid dispersion obtained by spray drying," International Journal of Pharmaceutics, vol. 271, no. 1-2, pp. 281-286, 2004.

[202] G. B. Elion, A. Kovensky, G. H. Hitchings, E. Metz, and R. W. Rundles, "Metabolic studies of allopurinol, an inhibitor of xanthine oxidase," Biochemical Pharmacology, vol. 15, no. 7, pp. 863-880, 1966.

[203] S. Itagaki, T. Kurokawa, C. Nakata et al., "In vitro and in vivo antioxidant properties of ferulic acid: a comparative study with other natural oxidation inhibitors," Food Chemistry, vol. 114, no. 2, pp. 466-471, 2009.

[204] W.-S. Chan, P.-C. Wen, and H.-C. Chiang, "Structure-activity relationship of caffeic acid analogues on xanthine oxidase inhibition," Anticancer Reseach, vol. 15, no. 3, pp. 703-707, 1995.

[205] Y.-C. Chang, F.-W. Lee, C.-S. Chen et al., "Structure-activity relationship of C6-C3 phenylpropanoids on xanthine oxidaseinhibiting and free radical-scavenging activities," Free Radical Biology \& Medicine, vol. 43, no. 11, pp. 1541-1551, 2007.

[206] F. Borges, E. Fernande, and F. Roleira, "Progress towards the discovery of xanthine oxidase inhibitors," Current Medicinal Chemistry, vol. 9, no. 2, pp. 195-217, 2002.

[207] H. Rubbo, R. Radi, and E. Prodanov, "Substrate inhibition of xanthine oxidase and its influence on superoxide radical production," BBA - General Subjects, vol. 1074, no. 3, pp. 386391, 1991.

[208] A. Suzuki, D. Kagawa, A. Fujii, R. Ochiai, I. Tokimitsu, and I. Saito, "Short- and long-term effects of ferulic acid on blood pressure in spontaneously hypertensive rats," American Journal of Hypertension, vol. 15, no. 4, pp. 351-357, 2002.

[209] L. Hlavačková, A. Janegová, O. Uličná, P. Janega, A. Černá, and P. Babál, "Spice up the hypertension diet - Curcumin and piperine prevent remodeling of aorta in experimental L-NAME induced hypertension," Journal of Nutrition and Metabolism, vol. 8, article no. 72, 2011.

[210] M. Kampa, V.-I. Alexaki, G. Notas et al., "Antiproliferative and apoptotic effects of selective phenolic acids on T47D human breast cancer cells: potential mechanisms of action," Breast Cancer Research, vol. 6, no. 2, pp. R63-R74, 2004.

[211] F. Yang, B.-R. Zhou, P. Zhang, Y.-F. Zhao, J. Chen, and Y. Liang, "Binding of ferulic acid to cytochrome $\mathrm{c}$ enhances stability of the protein at physiological $\mathrm{pH}$ and inhibits cytochrome cinduced apoptosis," Chemico-Biological Interactions, vol. 170, no. 3, pp. 231-243, 2007.

[212] V. P. Menon and A. R. Sudheer, "Antioxidant and antiinflammatory properties of curcumin," in The Molecular Targets and Therapeutic Uses of Curcumin in Health and Disease, pp. 105-125, Springer, 2007.

[213] T.-Y. Huang, C.-W. Hsu, W.-C. Chang, M.-Y. Wang, J.-F. Wu, and Y.-C. Hsu, "Demethoxycurcumin retards cell growth and induces apoptosis in human brain malignant glioma GBM 8401 cells," Evidence-Based Complementary and Alternative Medicine, vol. 2012, Article ID 396573, 11 pages, 2012.

[214] A. A. Reinke and J. E. Gestwicki, "Structure-activity relationships of amyloid beta-aggregation inhibitors based on curcumin: Influence of linker length and flexibility," Chemical Biology \& Drug Design, vol. 70, no. 3, pp. 206-215, 2007.

[215] S.-Y. Park, H.-S. Kim, E.-K. Cho et al., "Curcumin protected PC12 cells against beta-amyloid-induced toxicity through the inhibition of oxidative damage and tau hyperphosphorylation," Food and Chemical Toxicology, vol. 46, no. 8, pp. 2881-2887, 2008.

[216] F. Yang, G. P. Lim, A. N. Begum et al., "Curcumin inhibits formation of amyloid $\beta$ oligomers and fibrils, binds plaques, and reduces amyloid in vivo," The Journal of Biological Chemistry, vol. 280, no. 7, pp. 5892-5901, 2005.

[217] T. Hamaguchi, K. Ono, A. Murase, and M. Yamada, "Phenolic compounds prevent Alzheimer's pathology through different 
effects on the amyloid-beta aggregation pathway," The American Journal of Pathology, vol. 175, no. 6, pp. 2557-2565, 2009.

[218] R. Sultana, A. Ravagna, H. Mohmmad-Abdul, V. Calabrese, and D. A. Butterfield, "Ferulic acid ethyl ester protects neurons against amyloid $\beta$-peptide(1-42)-induced oxidative stress and neurotoxicity: relationship to antioxidant activity," Journal of Neurochemistry, vol. 92, no. 4, pp. 749-758, 2005.

[219] K. Ono, M. Hirohata, and M. Yamada, "Ferulic acid destabilizes preformed $\beta$-amyloid fibrils in vitro," Biochemical and Biophysical Research Communications, vol. 336, no. 2, pp. 444-449, 2005.

[220] M.-C. Kim, S.-J. Kim, D.-S. Kim et al., "Vanillic acid inhibits inflammatory mediators by suppressing NF- $\kappa \mathrm{B}$ in lipopolysaccharide-stimulated mouse peritoneal macrophages," Immunopharmacology and Immunotoxicology, vol. 33, no. 3, pp. 525-532, 2011.

[221] H. J. Kim, I. K. Hwang, and M. H. Won, "Vanillin, 4hydroxybenzyl aldehyde and 4-hydroxybenzyl alcohol prevent hippocampal CAl cell death following global ischemia," Brain Research, vol. 1181, no. 1, pp. 130-141, 2007.

[222] P. Anand, A. B. Kunnumakkara, R. A. Newman, and B. B. Aggarwal, "Bioavailability of curcumin: problems and promises," Molecular Pharmaceutics, vol. 4, no. 6, pp. 807-818, 2007.

[223] C. R. Ireson, D. J. Jones, S. Orr et al., "Metabolism of the cancer chemopreventive agent curcumin in human and rat intestine," Cancer Epidemiology, Biomarkers \& Prevention, vol. 11, no. 1, pp. 105-111, 2002.

[224] B. B. Aggarwal and B. Sung, "Pharmacological basis for the role of curcumin in chronic diseases: an age-old spice with modern targets," Trends in Pharmacological Sciences, vol. 30, no. 2, pp. 85-94, 2009.

[225] F. Zsila, Z. Bikádi, and M. Simonyi, "Unique, pH-dependent biphasic band shape of the visible circular dichroism of curcumin-serum albumin complex," Biochemical and Biophysical Research Communications, vol. 301, no. 3, pp. 776-782, 2003.

[226] S. I. Hoehle, E. Pfeiffer, A. M. Sólyom, and M. Metzler, "Metabolism of curcuminoids in tissue slices and subcellular fractions from rat liver," Journal of Agricultural and Food Chemistry, vol. 54, no. 3, pp. 756-764, 2006.

[227] M.-H. Pan, T.-M. Huang, and J.-K. Lin, "Biotransformation of curcumin through reduction and glucuronidation in mice," Drug Metabolism and Disposition, vol. 27, no. 4, pp. 486-494, 1999.

[228] T. M. A. Elattar and A. S. Virji, "The inhibitory effect of curcumin, genistein, quercetin and cisplatin on the growth of oral cancer cells in vitro," Anticancer Reseach, vol. 20, no. 3 A, pp. 1733-1738, 2000.

[229] M.-T. Huang, T. Lysz, T. Ferraro, T. F. Abidi, J. D. Laskin, and A. H. Conney, "Inhibitory effects of curcumin on in vitro lipoxygenase and cyclooxygenase activities in mouse epidermis," Cancer Research, vol. 51, no. 3, pp. 813-819, 1991.

[230] K. Ono, K. Hasegawa, H. Naiki, and M. Yamada, "Curcumin has potent anti-amyloidogenic effects for Alzheimer's $\beta$-amyloid fibrils in vitro," Journal of Neuroscience Research, vol. 75, no. 6, pp. 742-750, 2004.

[231] J. L. Arbiser, N. Klauber, . Rohan et al., "Curcumin is an in vivo inhibitor of angiogenesis," Molecular Medicine, vol. 4, no. 6, p. 376, 1998.

[232] M. M. Chan, H. Huang, M. R. Fenton, and D. Fong, "In vivo inhibition of nitric oxide synthase gene expression by curcumin, a cancer preventive natural product with anti-inflammatory properties," Biochemical Pharmacology, vol. 55, no. 12, pp. 19551962, 1998.
[233] C. Ireson, S. Orr, D. J. L. Jones et al., "Characterization of metabolites of the chemopreventive agent curcumin in human and rat hepatocytes and in the rat in vivo, and evaluation of their ability to inhibit phorbol ester-induced prostaglandin E2production," Cancer Research, vol. 61, no. 3, pp. 1058-1064, 2001.

[234] L. Baum, C. W. K. Lam, S. K. Cheung et al., "Six-month randomized, placebo-controlled, double-blind, pilot clinical trial of curcumin in patients with Alzheimer disease," Journal of Clinical Psychopharmacology, vol. 28, no. 1, pp. 110-113, 2008.

[235] Y. Tsai, W. Jan, C. Chien, W. Lee, L. Lin, and T. Tsai, "Optimised nano-formulation on the bioavailability of hydrophobic polyphenol, curcumin, in freely-moving rats," Food Chemistry, vol. 127, no. 3, pp. 918-925, 2011.

[236] L. P. Volak, S. Ghirmai, J. R. Cashman, and M. H. Court, "Curcuminoids inhibit multiple human cytochromes P450, UDP- glucuronosyltransferase, and sulfotransferase enzymes, whereas piperine is a relatively selective CYP3A4 inhibitor," Drug Metabolism and Disposition, vol. 36, no. 8, pp. 1594-1605, 2008.

[237] A.-L. Cheng, C. H. Hsu, J. K. Lin et al., "Phase I clinical trial of curcumin, a chemopreventive agent, in patients with high-risk or pre-malignant lesions," Anticancer Research, vol. 21, no. 48, pp. 2895-2900, 2000.

[238] G. M. Holder, J. L. Plummer, and A. J. Ryan, "The metabolism and excretion of curcumin (1,7-bis-(4-hydroxy3-methoxyphenyl)-1,6-heptadiene-3,5-dione) in the rat," Xenobiotica, vol. 8, no. 12, pp. 761-768, 1978.

[239] S. Shukla, G. T. MacLennan, P. Fu et al., "Nuclear factor- $\kappa B / p 65$ (Rel A) is constitutively activated in human prostate adenocarcinoma and correlates with disease progression," Neoplasia, vol. 6, no. 4, pp. 390-400, 2004.

[240] E. Ardite, J. Panés, M. Miranda et al., "Effects of steroid treatment on activation of nuclear factor $\kappa \mathrm{B}$ in patients with inflammatory bowel disease," British Journal of Pharmacology, vol. 124, no. 3, pp. 431-433, 1998.

[241] A. Garg and B. B. Aggarwal, "Nuclear transcription factor- $\kappa$ B as a target for cancer drug development," Leukemia, vol. 16, no. 6, pp. 1053-1068, 2002.

[242] F. R. Greten and M. Karin, “The IKK/NF- $\kappa$ B activation pathway - A target for prevention and treatment of cancer," Cancer Letters, vol. 206, no. 2, pp. 193-199, 2004.

[243] F. H. Sarkar and Y. Li, "NF-kappaB: A potential target for cancer chemoprevention and therapy," Frontiers in Bioscience, vol. 13, no. 8, pp. 2950-2959, 2008.

[244] J. Yan and J. M. Greer, "NF- $\kappa$ B, a potential therapeutic target for the treatment of multiple sclerosis," CNS and Neurological Disorders - Drug Targets, vol. 7, no. 6, pp. 536-557, 2008.

[245] J. A. Roman-Blas and S. A. Jimenez, "NF- $\kappa$ B as a potential therapeutic target in osteoarthritis and rheumatoid arthritis," Osteoarthritis and Cartilage, vol. 14, no. 9, pp. 839-848, 2006.

[246] M. Feldmann, E. Andreakos, C. Smith et al., "Is NF- $\kappa$ B a useful therapeutic target in rheumatoid arthritis?" Annals of the Rheumatic Diseases, vol. 61, supplement 2, pp. i13-i18, 2002.

[247] K. D. Brown, E. Claudio, and U. Siebenlist, "The roles of the classical and alternative nuclear factor $-\kappa \mathrm{B}$ pathways: potential implications for autoimmunity and rheumatoid arthritis," Arthritis Research \& Therapy, vol. 10, no. 4, article 212, 2008.

[248] F. R. Greten, L. Eckmann, T. F. Greten et al., "IKK $\beta$ links inflammation and tumorigenesis in a mouse model of colitisassociated cancer," Cell, vol. 118, no. 3, pp. 285-296, 2004. 
[249] X. Feng, H. Wang, S. Ye et al., "Up-regulation of microRNA126 may contribute to pathogenesis of ulcerative colitis via regulating NF-kappaB Inhibitor $\mathrm{I} \kappa \mathrm{B} \alpha$," PLoS ONE, vol. 7, no. 12, Article ID e52782, 2012.

[250] Y. M. Shah, X. Ma, K. Morimura, I. Kim, and F. J. Gonzalez, "Pregnane X receptor activation ameliorates DSS-induced inflammatory bowel disease via inhibition of NF- $\kappa$ B target gene expression," American Journal of Physiology-Gastrointestinal and Liver Physiology, vol. 292, no. 4, pp. G1114-G1122, 2007.

[251] S. Bacher and M. L. Schmitz, "The NF-KB pathway as a potential target for autoimmune disease therapy," Current Pharmaceutical Design, vol. 10, no. 23, pp. 2827-2837, 2004.

[252] J. W. Christman, L. H. Lancaster, and T. S. Blackwell, "Nuclear factor $\kappa \mathrm{B}$ : a pivotal role in the systemic inflammatory response syndrome and new target for therapy," Intensive Care Medicine, vol. 24, no. 11, pp. 1131-1138, 1998.

[253] S. S. Makarov, "NF- $\kappa$ b as a therapeutic target in chronic inflammation: recent advances," Molecular Medicine Today, vol. 6, no. 11, pp. 441-448, 2000.

[254] T. Ishrat, M. N. Hoda, M. B. Khan et al., "Amelioration of cognitive deficits and neurodegeneration by curcumin in rat model of sporadic dementia of Alzheimer's type (SDAT)," European Neuropsychopharmacology, vol. 19, no. 9, pp. 636-647, 2009.

[255] Z. Liu, Y. Yu, X. Li, C. A. Ross, and W. W. Smith, "Curcumin protects against $\mathrm{A} 53 \mathrm{~T}$ alpha-synuclein-induced toxicity in a PC12 inducible cell model for Parkinsonism," Pharmacological Research, vol. 63, no. 5, pp. 439-444, 2011.

[256] G. Scapagnini, C. Colombrita, M. Amadio et al., "Curcumin activates defensive genes and protects neurons against oxidative stress," Antioxidants \& Redox Signaling, vol. 8, no. 3-4, pp. 395403, 2006.

[257] Y.-G. Zhu, X. C. Chen, Z. Z. Chen et al., "Curcumin protects mitochondria from oxidative damage and attenuates apoptosis in cortical neurons," Acta Pharmacologica Sinica, vol. 25, pp. 1606-1612, 2004.

[258] Y. Wang and M. A. Beydoun, "The obesity epidemic in the United States-gender, age, socioeconomic, racial/ethnic, and geographic characteristics: a systematic review and metaregression analysis," Epidemiologic Reviews, vol. 29, no. 1, pp. 628, 2007.

[259] P. T. James, R. Leach, E. Kalamara, and M. Shayeghi, "The Worldwide Obesity Epidemic," Obesity Research, vol. 9, no. S11, pp. 228S-233S, 2001.

[260] J. C. Seidell, "Obesity, insulin resistance and diabetes-a worldwide epidemic," British Journal of Nutrition, vol. 83, supplement 1, pp. S5-S8, 2000.

[261] P. Vitaglione, R. Barone Lumaga, R. Ferracane et al., "Curcumin bioavailability from enriched bread: The effect of microencapsulated ingredients," Journal of Agricultural and Food Chemistry, vol. 60, no. 13, pp. 3357-3366, 2012.

[262] B. T. Kurien and R. H. Scofield, "Oral administration of heat-solubilized curcumin for potentially increasing curcumin bioavailability in experimental animals," International Journal of Cancer, vol. 125, no. 8, pp. 1992-1993, 2009.

[263] J. Shaikh, D. D. Ankola, V. Beniwal, D. Singh, M. N. V. Ravi Kumar, and J. Pharm, "Nanoparticle encapsulation improves oral bioavailability of curcumin by at least 9-fold when compared to curcumin administered with piperine as absorption enhancer," European Journal of Pharmaceutical Sciences, vol. 37, pp. 223-230, 2009.
[264] P. A. Subramani and V. R. Narala, "Challenges of curcumin bioavailability: Novel aerosol remedies," Natural Product Communications (NPC), vol. 8, no. 1, pp. 121-124, 2013.

[265] M. M. Yallapu, M. C. Ebeling, N. Chauhan, M. Jaggi, and S. C. Chauhan, "Interaction of curcumin nanoformulations with human plasma proteins and erythrocytes," International Journal of Nanomedicine, vol. 6, pp. 2779-2790, 2011.

[266] S. Bisht and A. Maitra, "Systemic delivery of curcumin: 21st century solutions for an ancient conundrum," Current Drug Discovery Technologies, vol. 6, pp. 192-199, 2009.

[267] C. Chen, T. D. Johnston, H. Jeon et al., "An in vitro study of liposomal curcumin: Stability, toxicity and biological activity in human lymphocytes and Epstein-Barr virus-transformed human B-cells," International Journal of Pharmaceutics, vol. 366, no. 1-2, pp. 133-139, 2009.

[268] G. Liang, L. Shao, Y. Wang et al., "Exploration and synthesis of curcumin analogues with improved structural stability both in vitro and in vivo as cytotoxic agents," Bioorganic \& Medicinal Chemistry, vol. 17, pp. 2623-2631, 2009.

[269] A. Jacob, R. Wu, M. Zhou, and P. Wang, "Mechanism of the antiinflammatory effect of curcumin: PPAR- $\gamma$ activation," PPAR Research, vol. 2007, Article ID 89369, 5 pages, 2007.

[270] L. Shen and H. Ji, "The pharmacology of curcumin: is it the degradation products?" Trends in Molecular Medicine, vol. 18, no. 3, pp. 138-144, 2012. 


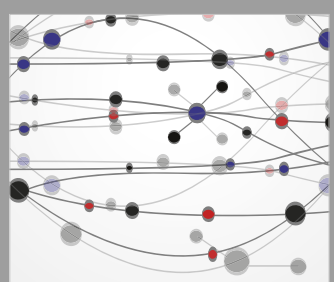

The Scientific World Journal
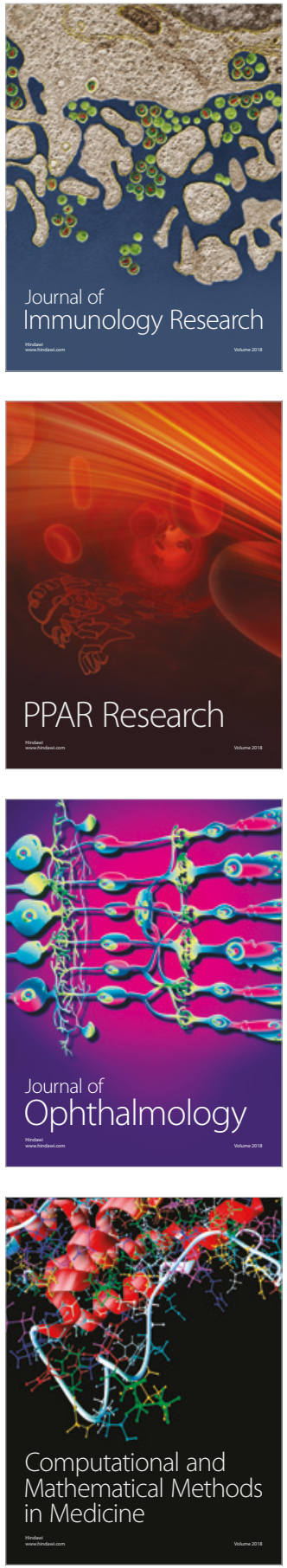

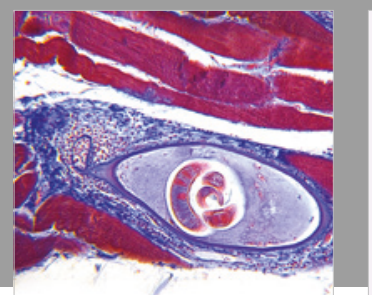

Gastroenterology Research and Practice

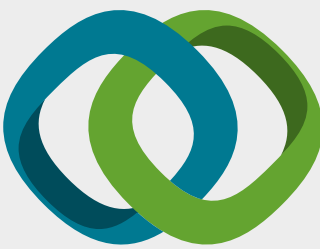

\section{Hindawi}

Submit your manuscripts at

www.hindawi.com
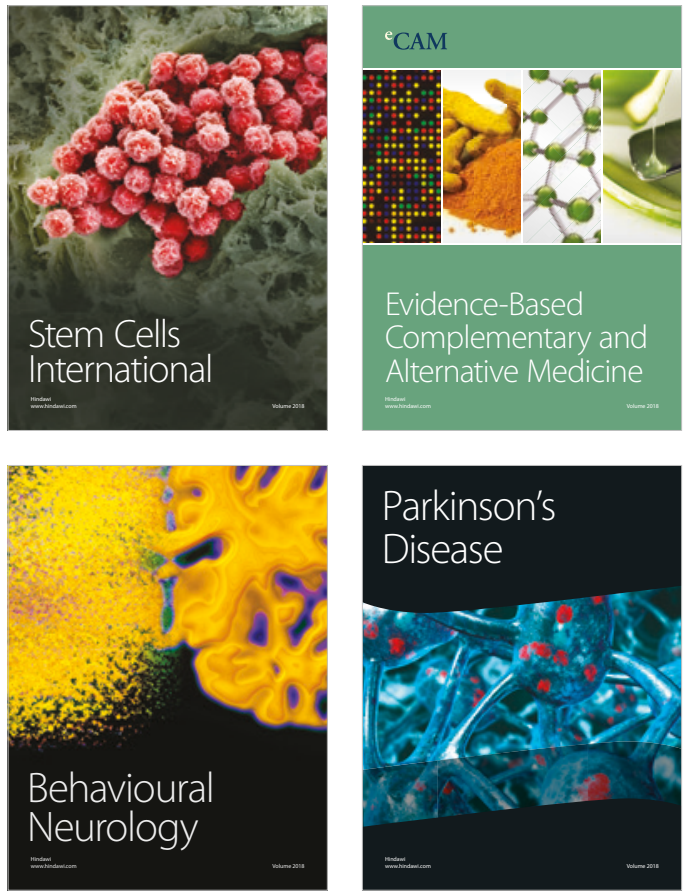

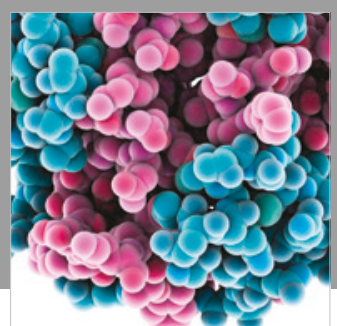

ournal of

Diabetes Research

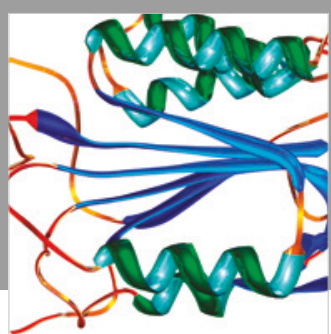

Disease Markers
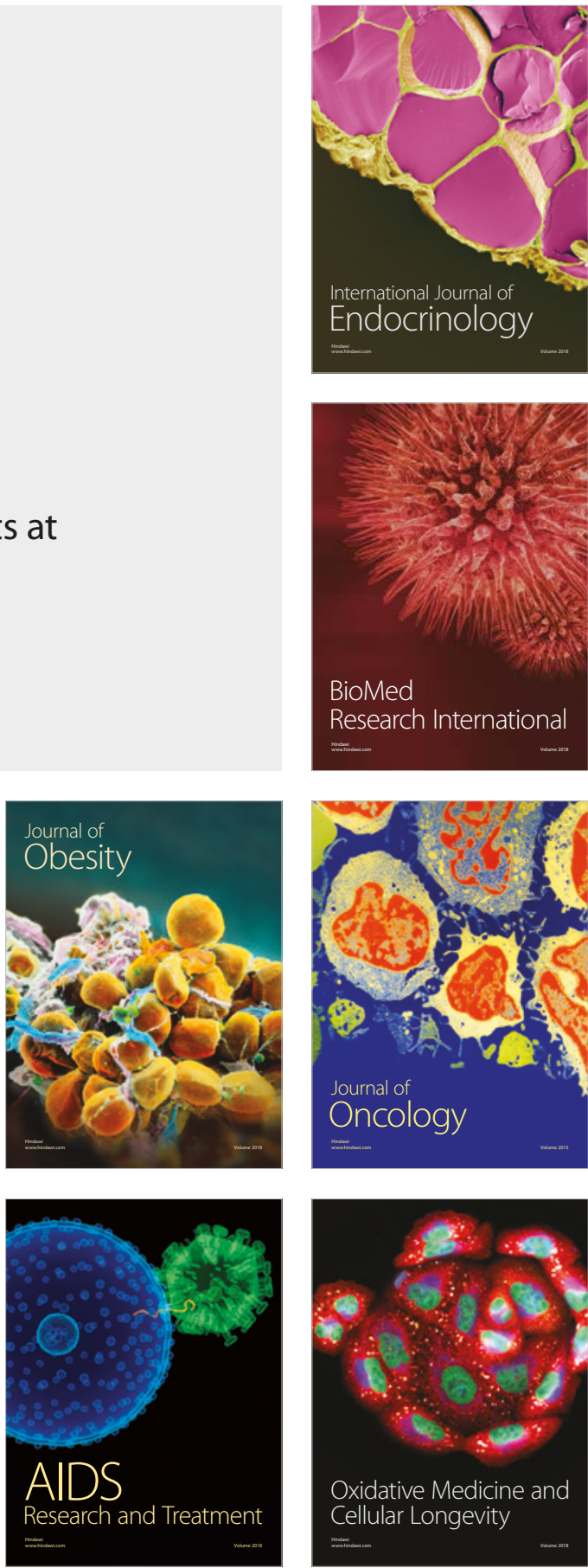